US Army Corps of Engineers ${ }_{\circledast}$

Engineer Research and

Development Center

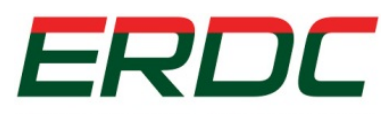

INNOVATIVE SOLUTIONS for a safer, better world

Foreign Technology Assessment Support Program

\title{
Method of Construction for Geopolymer Soil Stabilized Platforms
}

Ghassan K. Al-Chaar, Peter B. Stynoski, Matthew M. Landi,

December 2017

and Marion L. Banko

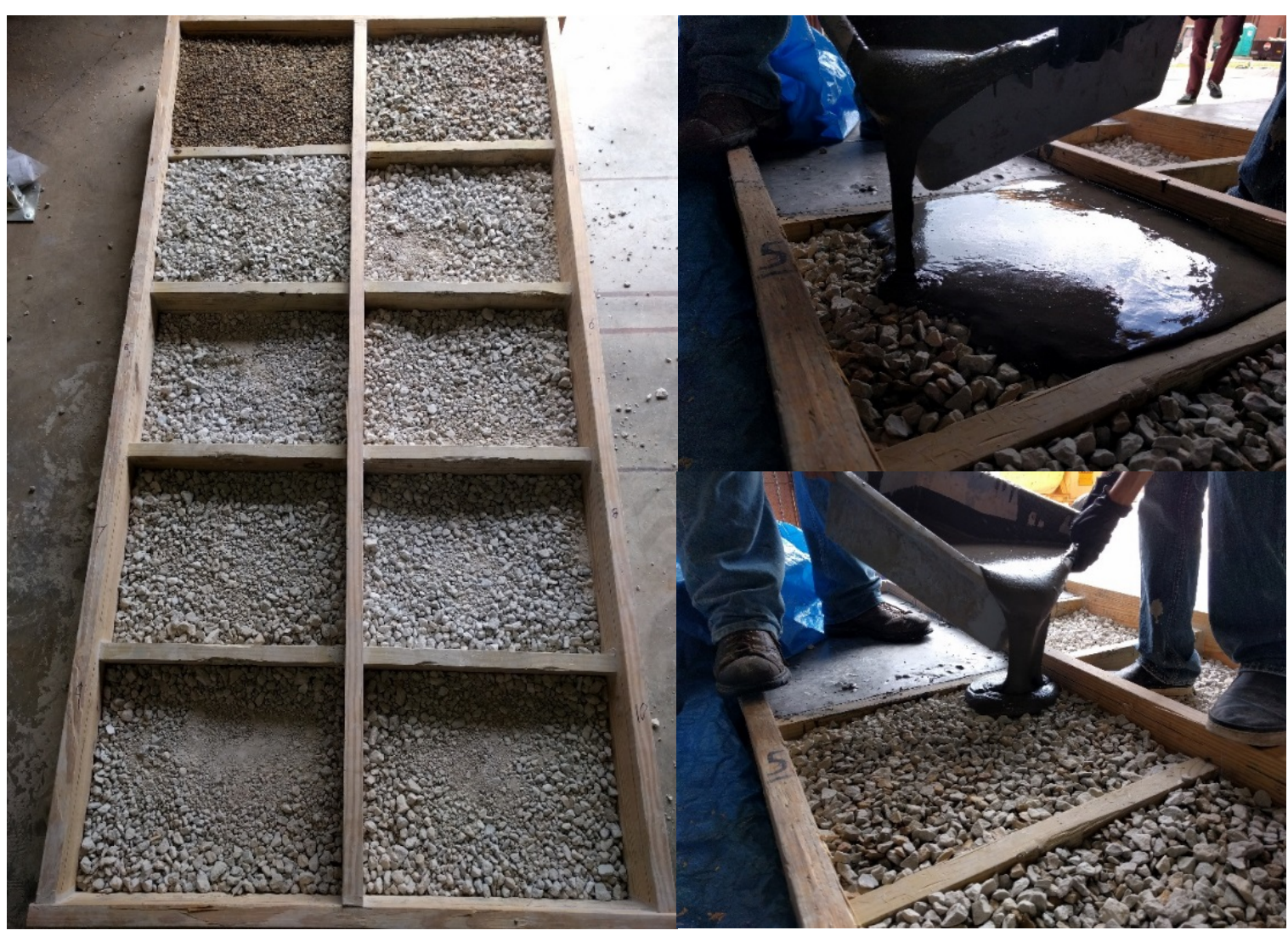


The U.S. Army Engineer Research and Development Center (ERDC) solves the nation's toughest engineering and environmental challenges. ERDC develops innovative solutions in civil and military engineering, geospatial sciences, water resources, and environmental sciences for the Army, the Department of Defense, civilian agencies, and our nation's public good. Find out more at www.erdc.usace.army.mil.

To search for other technical reports published by ERDC, visit the ERDC online library at http://acwc.sdp.sirsi.net/client/default. 


\section{Method of Construction for Geopolymer Soil Stabilized Platforms}

Ghassan K. Al-Chaar, Peter B. Stynoski, Matthew M. Landi, and Marion L. Banko Construction Engineering Research Laboratory

U.S. Army Engineer Research and Development Center 2902 Newmark Drive

Champaign, IL 61822

Final report

Approved for public release; distribution is unlimited.

Prepared for U.S. Army Corps of Engineers

Washington, DC 20314-1000

Under Project 461088, "Method of Construction for Geopolymer Soil Stabilized Platforms" 


\section{Abstract}

To protect valuable assets from corrosive environments and associated maintenance issues, the Department of Defense (DoD) military services prefer to store vehicles, aircraft, and equipment in controlled environments, such as engineered tension fabric structures. However, this type of structure requires a solid base, which is often made of concrete and when left behind, it creates real property issues. To address this issue, an alternative method of construction for stabilizing soil was developed and tested by ERDC-CERL during FY17 by using a gravel base and stabilizing it with geopolymer. In this method, mixtures of geopolymer and sand are percolated into loose gravel beds to produce hard surfaces that exhibit nearly the same strength as ordinary concrete. Advantages of this technique include lack of batching, repurposing of industrial waste products, and ease of installation. This report discusses laboratory demonstrations performed by ERDC-CERL to determine a useful range of component ratios, characterize the critical properties of the gravel bed, and identify the most successful application methods. Results indicate that a geopolymer mortar with $35 \%$ wt sand, or $45 \%$ wt sand with additional water, can effectively percolate through an ASTM \#6 gravel bed, resulting in a strong, stabilized platform.

DISCLAIMER: The contents of this report are not to be used for advertising, publication, or promotional purposes. Citation of trade names does not constitute an official endorsement or approval of the use of such commercial products. All product names and trademarks cited are the property of their respective owners. The findings of this report are not to be construed as an official Department of the Army position unless so designated by other authorized documents. 


\section{Contents}

Abstract.................................................................................................................................. if

Figures and Tables................................................................................................................

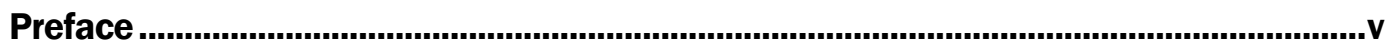

Unit Conversion Factors...................................................................................................

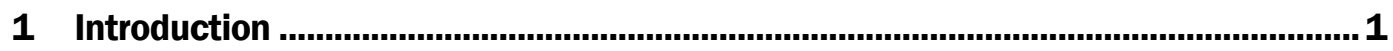

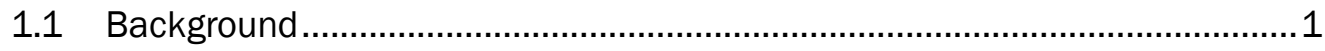

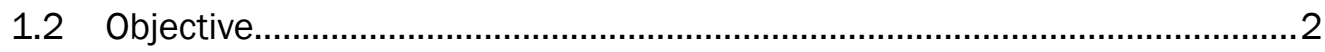

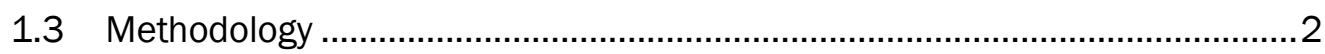

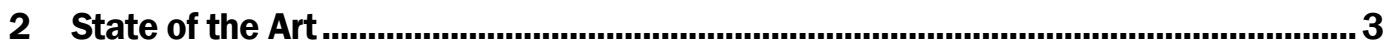

2.1 Geopolymers ......................................................................................

2.2 Materials used for soil stabilization......................................................... 4

2.2.1 Organic soil stabilizers................................................................................. 4

2.2.2 Inorganic soil stabilizers ................................................................................. 5

2.3 Method of construction using existing soil stabilizers ............................... 5

2.3.1 Organic soil stabilizers .................................................................................. 5

2.3.2 Inorganic soil stabilizers .................................................................................. 5

2.4 History of construction using geopolymer concrete ...................................6

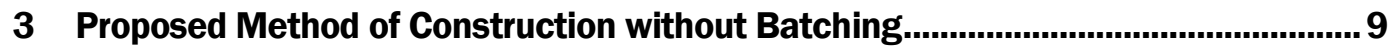

3.1 Materials, Methods and Results............................................................11

3.1.1 Admixtures............................................................... Error! Bookmark not defined.

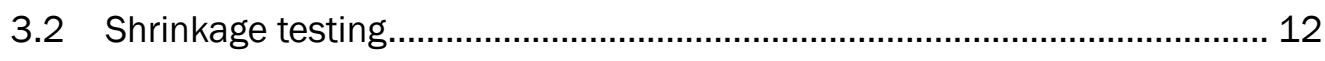

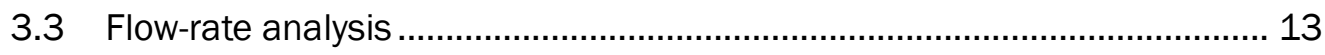

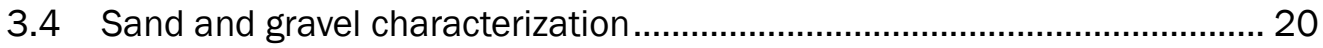

3.5 Test pavement ................................................................................. 23

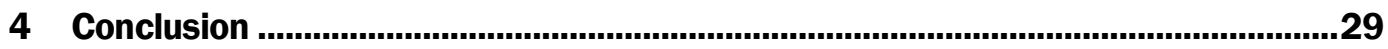

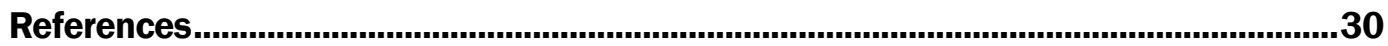

Report Documentation Page 


\section{Figures and Tables}

\section{Figures}

Figure 1. Wet jet end mixing tool (left), and soil cutting wheels (right); images taken from the Federal Highway Administration Design Manual (Bruce 2013)

Figure 2. Batching equipment used by Wagners in Australia for EFC (Wagners 2014; Glasby 2015).

Figure 3. Surface course of pea gravel in saturated surface dry (SSD) condition (left); geopolymer mortar seeping through the gravel (middle); Cross section of the test pavement after geopolymer cures showing stabilized base course and surface course (right). 9

Figure 4. Liquid tote (left); hopper gun (right). ……….....................................................10

Figure 5. Mass \% vs time of geopolymer mortar when coated with various commercially available evaporation retardants.

Figure 6. Strain due to drying shrinkage over time......................................................13

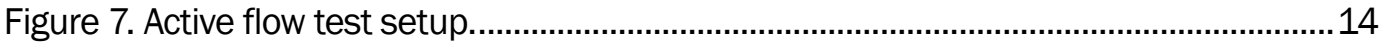

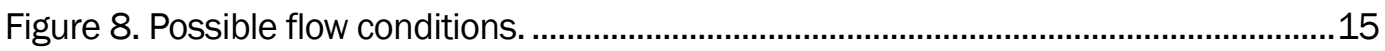

Figure 9. Flow comparison over time, with spout diameters of 1" (top), 3/4"

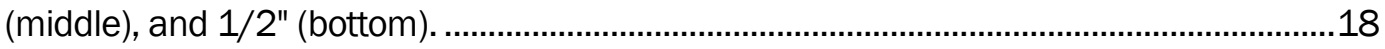

Figure 10. Comparison of mathematical prediction to experimental data.........................20

Figure 11. Base course (left); approximate \#67 gradation (right). .....................................21

Figure 12. Void test side view (left); birds-eye view (right).....................................................21

Figure 13. Void content of gradations measured by mass of water fill...............................21

Figure 14. Sand grain size distribution. ..............................................................................22

Figure 15. Test plan (left); boxes 1-3 filled, boxes 4-10 show compacted base

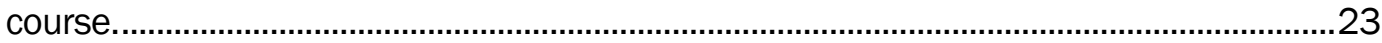

Figure 16. Initial pour starting in the corner (left), and working inward (right)...................24

Figure 17. Cutting cores (top left); Core compilation (top right); box with half the pavements cored and half removed (bottom). ..............................................................25

Figure 18. Showing the 3-point bend test (left); compression test (right). ........................26

Figure 19. Fractured beams (top); crushed cylinders (bottom)........................................2

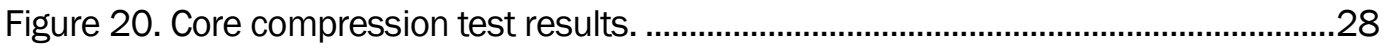

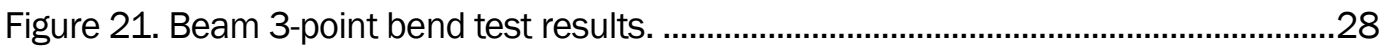

\section{Tables}

Table 1: Theoretical flow-rate calculation for 30 \%wt sand geopolymer mortar. ................15

Table 2: Theoretical volumetric flow rate of geopolymer mortar..........................................16

Table 3: Experimentally determined volumetric flow rate of geopolymer mortar. ...............17

Table 4. Sand gradation fineness modulus. ......................................................................22 


\section{Preface}

This study was conducted for the Foreign Technology Assessment Support Program under Project 461088, "Method of Construction for Geopolymer Soil Stabilized Platforms.” The sponsor's technical monitor was Mr. Sean Jankiewicz.

The work was performed by the Materials and Structures Branch of the Facilities Division (CFM), U.S. Army Engineer Research and Development Center, Construction Engineering Research Laboratory (ERDC-CERL). At the time of publication, Ms. Vicki L. Van Blaricum was Chief, CEERDCFM; Mr. Donald K. Hicks was Chief, CEERD-CF; and Mr. Kurt Kinnevan, CEERD-CZT was the Technical Director for Adaptive and Resilient Installations. The Interim Deputy Director of ERDC-CERL was Ms. Michelle J. Hanson, and the Interim Director was Dr. Kirankumar Topudurti.

The authors would like to acknowledge Professor Waltraud M. Kriven at the University of Illinois at Urbana-Champaign and the Australian-based company Zeobond for their consultation contributions as geopolymer experts. The authors would also like to acknowledge Mr. Kaushik Sankar, Mr. Patrick Keane, Mr. Ameer Barbour, Mr. Cameron Schaffer, Mr. David Johnson, and Ms. Sarah Chahine for their efforts in laboratory setup, sample preparations, laboratory testing, and data collection.

The Commander of ERDC was COL Bryan S. Green, and the Director was Dr. David W. Pittman. 


\section{Unit Conversion Factors}

\begin{tabular}{|l|c|l|}
\hline Multiply & By & To Obtain \\
\hline cubic inches & $1.6387064 \mathrm{E}-05$ & cubic meters \\
\hline degrees Fahrenheit & $(\mathrm{F}-32) / 1.8$ & degrees Celsius \\
\hline inches & 0.0254 & meters \\
\hline microinches & 0.0254 & micrometers \\
\hline ounces (mass) & 0.02834952 & kilograms \\
\hline ounces (U.S. fluid) & $2.957353 \mathrm{E}-05$ & cubic meters \\
\hline pounds (force) & 4.448222 & newtons \\
\hline pounds (force) per square inch & 6.894757 & kilopascals \\
\hline pounds (mass) & 0.45359237 & kilograms \\
\hline pounds (mass) per cubic inch & $2.757990 \mathrm{E}+04$ & kilograms per cubic meter \\
\hline square inches & $6.4516 \mathrm{E}-04$ & square meters \\
\hline square miles & $2.589998 \mathrm{E}+06$ & square meters \\
\hline
\end{tabular}




\section{Introduction}

\subsection{Background}

The Department of Defense (DoD) has a massive inventory of ground vehicles, aircraft, and large equipment that serve many different purposes and operate in a variety of environments. This inventory has critical parts that are vulnerable to corrosion from many of those environments. Their mechanical parts and electrical components, which are vital to readiness and mission completion, are subject to failure from the effects of corrosion. However, significant reduction in corrosion and required corrosion maintenance is achieved when these assets are stored in controlled and/or dehumidified storage areas, such as engineered tension fabric structures. The tensioned fabric and the support frame form a single integral structural unit that is low in cost and quick to construct. However, these structures must be erected on a supporting concrete foundation that is both expensive to install and designed to be permanent. Although the structures are intended for temporary use, the slabs and utilities infrastructure are accountable as DoD real property. When the engineered tension fabric structures are eventually dismantled and removed from the site, the Directorate of Public Works (DPW) is left with maintaining and/or disposing of the real property. Because of this, some installation managers considered the vacated sites as unwanted burdens.

These issues may be resolved by using a geopolymer soil stabilized platform to replace the concrete foundation. The use of a geopolymer soil stabilized platform eliminates the need for concrete and its associated permanency, and it allows the site to be easily returned to its native state when it is no longer needed. Demonstrating the use of a geopolymer soil stabilized platform will validate the use of this technology in reducing the effect of corrosion on asset readiness.

However, knowledge of the construction methods and necessary equipment needed to accommodate the properties of the geopolymer mixture are significantly lacking within the private sector and the DoD. This lack of knowledge may be resolved through using both laboratory and in-situ testing to identify the properties of the geopolymer mixture and then determining the method of construction suitable for each design while considering mixture characteristics and site location. 


\subsection{Objective}

This effort is to validate a method of construction suitable for applying a variety of geopolymer concrete mixture properties. Exploration of additional features of the equipment and mixing process that would result in monolithic platforms placement, and modification of the construction equipment to enhance the efficiency and the feasibility of the technique were covered.

\subsection{Methodology}

A flowable geopolymer mortar was prepared according to the procedure outline in the Appendix of ERDC-CERL TR-17-9, "Development and Testing of Geopolymers for Soil Stabilization on Military Installations." The geopolymer mortar was then poured over ten $2 \times 2 \mathrm{ft}$ boxes of wellgraded course aggregate. The geopolymer mortar was allowed to seep into the surface course of the pavements, filling the voids as it seeped, and resulting in a 4-inch thick surface pavement.

Several factors were evaluated to determine the suitability of geopolymer mortar for pavement applications. The first was the type of surface course needed to allow the geopolymer to fully penetrate the entire depth. The second was the geopolymer mortar mixture and the ratios of water and sand that would allow the geopolymer proper flowability to seep. The third was various types of reinforcement in the surface course to evaluate potential strength gains and seepage inhibitions. Chapters 3 and 3.1 detail the experimental processes and results of each of these factors. 


\section{State of the Art}

\subsection{Geopolymers}

Geopolymers (or polysialates) are a relatively new class of ceramic-like materials that can be made from a liquid phase under ambient temperatures. They are an inorganic polymer and contain a rigid, hydrated, nanoporous, nanoparticulate, alumino-silicate gel, which results in a threedimensional (3D) structure that is amorphous, cross-linked, impervious, and acid-resistant. This general class of ceramic materials is distinct and separate from other geopolymers that employ alkali-activation such as CASH (calcium aluminosilicate hydrate), and NASH (sodium aluminosilicate hydrate). Geopolymers have been used as coatings, thermal barriers, and adhesives for a number of years, and their chemical and mechanical bonding mechanisms, microstructure, and chemical composition are beginning to be better understood. In particular, geopolymerization reaction kinetics and high-temperature transformations have been studied. The detailed atomic structure of geopolymer has begun to be investigated via SAS (small angle scattering) pair distribution function analysis. Publications to date take advantage of high-intensity synchrotron X-ray irradiation, in part to explore real-time kinetics. Together, SAS and synchrotron analysis form a complete picture of geopolymer atomic structure and structural reaction to kinetic disturbances.

Benefits of using geopolymers, depending on site location, include having a low cost for both the bulk constituent material inputs and their combined mix preparation. Often, materials that are otherwise treated as waste products (e.g., Type F [low calcium] fly ash, red mud, blast furnace slag, etc.) can be used from local or regional sources. Additionally, this reuse of waste products avoids potential adverse spills and environmental impacts. A further sustainability advantage is that the mix and use of geopolymers produces only $25 \%$ of the $\mathrm{CO}_{2}$ gas liberated by producing a comparable amount of Portland cement. In addition, the mechanical properties of geopolymers are similar, if not slightly superior, to those of cements and concretes.

Geopolymer soil stabilization is a method of stabilizing and strengthening the in-situ soil by using alternative supplemental cementitious materials (SCM). The geopolymer material uses SCMs vs. Portland cement and may 
be designed to include local ingenious materials, especially in platform application, without the expensive cost of importing or shipping Portland cement. Globally, there is an increased demand for concrete to meet infrastructure developments projects; however, geopolymer is gaining ground as a strong and highly suitable replacement for Portland cement concrete. The only drawback is that using traditional concrete methods and equipment during construction may not be fully suitable for geopolymer applications.

Due to its concrete-like strength, in-situ geopolymer soil stabilization can be used to provide a solid base for erecting temporary facilities. By designing a geopolymer concrete mix that achieves the necessary mechanical properties for this type of application, it is expected that initial costs for geopolymer-stabilized slabs in remote geographical regions will be significantly lower compared to bringing in Portland concrete, whether locally or from a considerable distance. In addition, it capitalizes on the ability to achieve natural cementation in geographical areas that have glassy soil constituents (e.g., sand and volcanic material). This technology may also be applicable for particular areas of operation where conventional materials, such as Portland cement, are difficult and costly to obtain.

\subsection{Materials used for soil stabilization}

Soil stabilization can be achieved by altering the physical nature of the soil by vibration, compaction, and/or improving gradation of particle size. These methods are broadly classified as mechanical soil stabilization methods because they alter the physical properties of soil (Makusa 2012). In addition to mechanical methods, further improvement in soil stabilization can be achieved through chemical methods, such as adding binders to weak soils (Rogers 1996). Some of the common soil stabilizer materials are discussed in the subsections below.

\subsubsection{Organic soil stabilizers}

OPSDIRT is a commercially-available product designed to be placed on unpaved roads for dust control. According to its material safety data sheets, OPS25 is a vinyl-acrylic copolymer containing vinyl acetate activator, plasticizers, and volatile drying agents that include alkylated bisphenol A, tri-isobutylene, and polyglycol esters; some of the components of OPS25 are subject to environmental, health, and safety regulations. OPS30 is a more user-friendly product with only small fractions of acrylates and a 
proprietary plasticizing component. The product appears, smells, and flows similarly to wood or school glues (Al-Chaar 2017).

\subsubsection{Inorganic soil stabilizers}

Cement has been traditionally used as a soil stabilizer because of its availability and ease of application. Cement-stabilized soil has decreased plasticity, decreased volume expansion, and increased strength relative to virgin soil (Makusa 2012). Class $\mathrm{C}$ fly ash is a common inorganic soil stabilizer that is currently in use for stabilizing low-plasticity sandy soil. The time between mixing and compaction must be as short as possible (less than 1 hour) when class $\mathrm{C}$ fly ash is used as a soil stabilizer. Lime is a stabilizer used for clayey soil. The moisture content must be much higher than optimum in clayey soil for lime to work as a stabilizer. Cement kiln dust and lime kiln dust are other common soil stabilizers. The strength of stabilized soil is affected by several factors such as organic matter, sulfates, carbon dioxide, sulfides, and other deleterious materials (Makusa 2012).

\subsection{Method of construction using existing soil stabilizers}

\subsubsection{Organic soil stabilizers}

The optimal moisture content of the soil is determined, and then OPSDirt (generally a few \%wt) is added and mixed with the soil. This mixture is allowed to cure for a few days. The method of soil stabilization by OPSDirt was discussed in detail in a previous technical report (Al-Chaar 2017).

\subsubsection{Inorganic soil stabilizers}

The method of soil stabilization by using inorganic soil stabilizers can be found in the state-of-the-art review (Makusa 2012), but certain relevant points from the review are summarized here. In-situ soil stabilization methods involve on-site soil improvement by applying soil stabilizers without removing the bulk soil. It is generally accomplished by injecting a stabilizer (dry or wet form) into the soil. Depending on the depth of soil treatment, the in-situ stabilization may be classified as either deep mixing method or mass stabilization. The aim of deep mixing method is to produce the stabilized soil mass which may interact with natural soil and not to produce a stiff stabilized soil mass, like a rigid pile, which may independently carry the design load. Wet mixing applications involve binder turned into slurry form, which is then injected into the soil through the nozzles located at the end of a soil auger (Massarsch 2005). Wet-mixing 
application equipment is shown in Figure 1. In this method, the mixing tool consists of a drilling rod, transverse beams, and a drill end with head.

Figure 1. Wet jet end mixing tool (left), and soil cutting wheels (right); images taken from the Federal Highway Administration Design Manual(Bruce 2013).

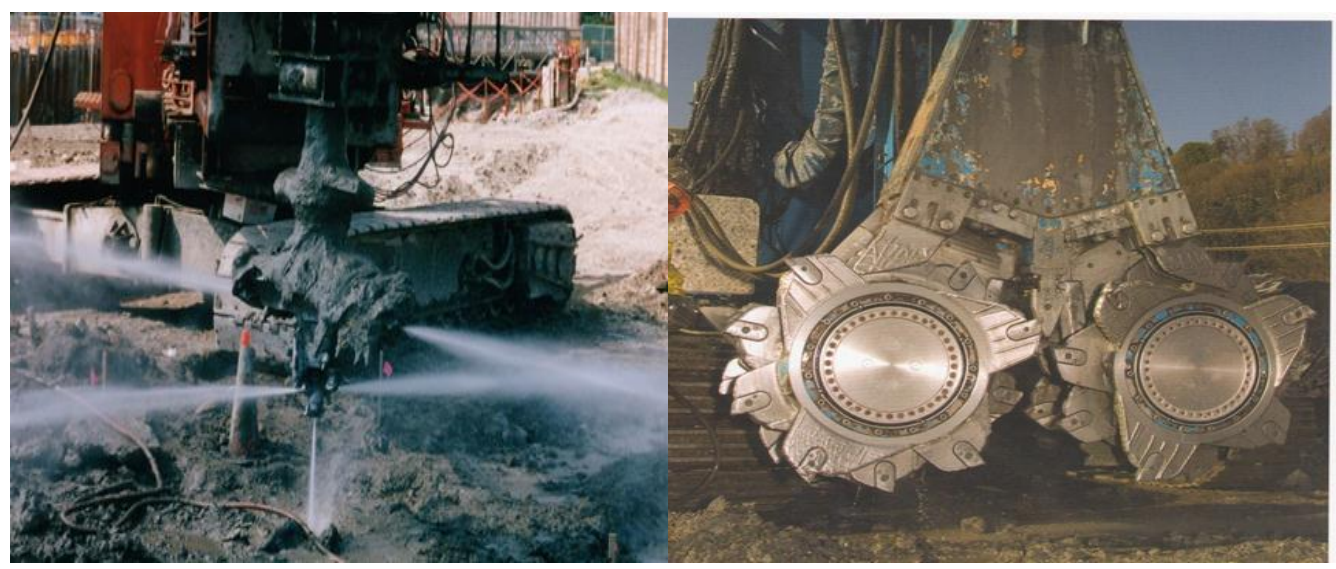

Mass stabilization is shallow when compared with the deep stabilization method in which the entire volume of soft soil can be stabilized to a prescribed depth. The mass stabilization technique is relatively new and is highly suited for the stabilization of high-moisture content such as clay, silty, organic soils and contaminated sediments (Stab 2002; Hayward 2012). Remediation of most deposits of contaminated dredged sediments, organic soils, and waste sludge usually make use of the mass stabilization method (Keller 2011). The method provides an alternative to traditional methods of soil improvement, such as removal and replacement techniques. The blending of the soil mass may be achieved by either use of excavator mounted mixing tools, with unique shuttles pneumatically delivering the binder to the head of the mixing tool and into the mix zone, or by self-injection of binder into a rotating auger or mixing head in the soil (Makusa 2012).

\subsection{History of construction using geopolymer concrete}

Slag-based alkaline cement concretes have been used in the Ukraine in the 1930s. They were used in multi-rise buildings (1950s), sewer pipes (1960s), and railway sleepers (1980s) (Wagners 2014). Geopolymers are chemically distinct from alkaline cements and are generally processed by mixing alkali silicate with an amorphous aluminosilicate precursor(s) like metakaolin, fly ash, and/or slag. This results in a three-dimensional solid aluminosilicate structure which is strong and durable [Q4(nAl) $(\mathrm{n}=1$ to 4$)]$ (Davidovits 2008). Geopolymers can be prepared using similar high shear mixers that 
are used for mixing ordinary Portland Cement (OPC). Previous geopolymer projects include the Toowoomba Wellcamp airport in Australia, a retaining wall project (precast panels), bridge decks, tennis courts, weighbridge slabs, and private and public pavements (Wagners 2014; Glasby 2015).

Generally, large-scale applications involved batching raw materials to make geopolymer concrete. Geopolymer concrete production for the airport project was accomplished using a twin mobile wet mix batch plant as shown in Figure 2 (top and middle left). This is reported to be a modification of the standard concrete production plant to accommodate the alkali silicate solution (Glasby 2015). Since this project used wet mix production, several dumper trucks were used to feed the geopolymer concrete to a slip form paver machine, as shown in Figure 2 (middle center and bottom) (Glasby 2015). Some of the other equipment used for batching geopolymer (marketed as "Earth Friendly Concrete" [EFC] by Wagners, Australia) is also shown in Figure 2.

Figure 2. Batching equipment used by Wagners in Australia for EFC (Wagners 2014; Glasby 2015).

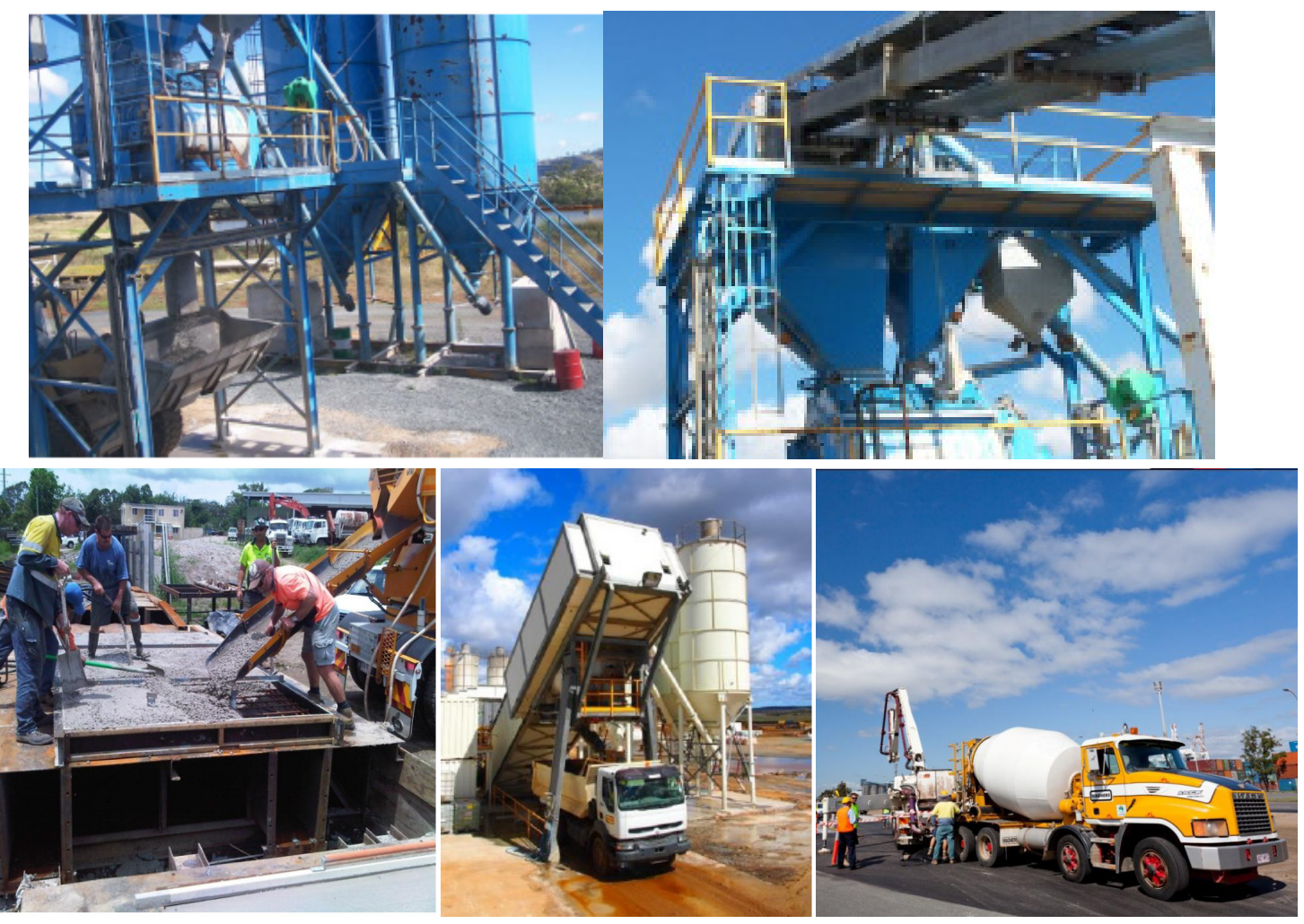



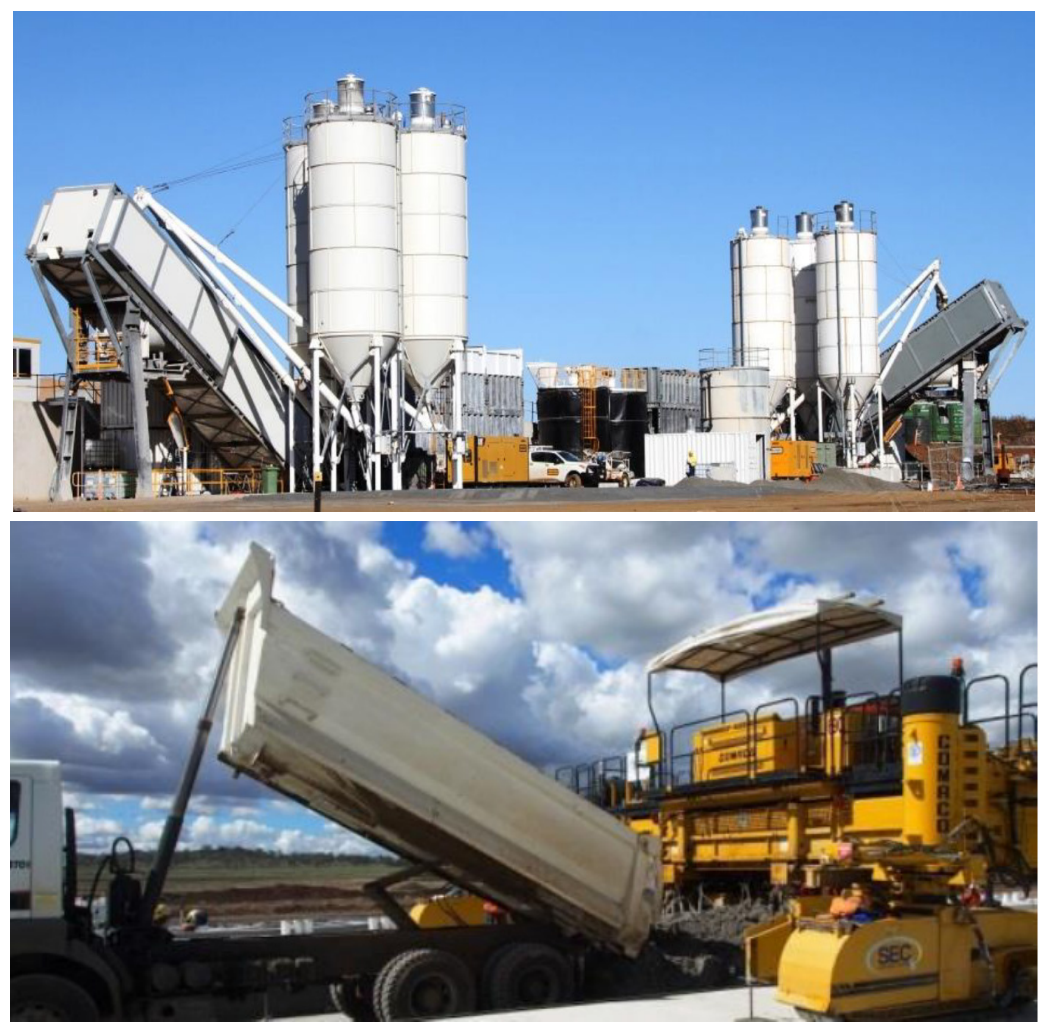


\section{Proposed Method of Construction without Batching}

This project proposed and evaluated a novel method of constructing the surface course of a pavement by using geopolymer concrete. This method avoids batching to reduce the use of energy and need for specialized equipment. A flowable geopolymer mortar mixture was prepared and poured on a bed of well-graded coarse aggregate. As the mortar seeps through the coarse aggregate, it fills the voids. This process avoids the need to batch mix binder and aggregates in a large mixer or truck. The base course was built using well-graded and compacted coarse aggregate with a stabilizer, similar to a standard Class II base. A Class II base course is characterized by aggregates made of a specific gradation of different rock sizes, based on the percent of aggregate retained on specific sieves. Class II base course is also specifically used for road applications.

The conceptual design is illustrated in Figure 3, where a 4 \%wt OPC stabilized sand was used as a base course. Geopolymer cement containing $15 \%$ wt sodium silicate solution, $85 \%$ wt fly ash and slag, was poured on loosely laid pea gravel in saturated surface dry condition. This was done on a $1 \times 1 \times 6$ in. mold, and the simulated pavement was cured in a sealed plastic bag with a wet cloth for 24 hours.

Figure 3. Surface course of pea gravel in saturated surface dry (SSD) condition (left); geopolymer mortar seeping through the gravel (middle); Cross section of the test pavement after geopolymer cures showing stabilized base course and surface course (right).

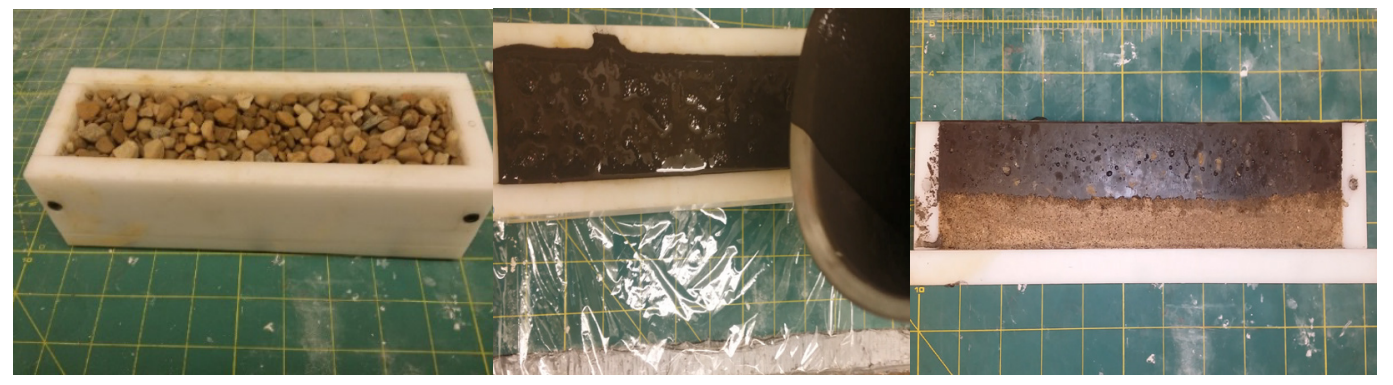

A liquid tote secured to a truck can be used for medium- to large-scale construction (Figure 4 left). The geopolymer mortar can be poured into the tote and subsequently poured on the gravel bed by opening the valve in the tote and moving the truck. Alternatively, a nozzle may be connected to the valve in the tote, and the geopolymer mortar can be sprayed on the 
gravel bed by using a hopper gun, as shown in Figure 4 (right). However, care must be taken if geopolymer is sprayed, because water is lost from the geopolymer during spraying.

Optimal pavement quality is achieved in two pours, which allows the geopolymer time for the first pass to seep through the surface course onto the base course. One may consider vibrating the geopolymer to improve flowability and accelerate seepage. After the geopolymer is poured on the gravel bed, it is important to cover the pavement with a wet burlap and/or plastic sheet to prevent the water in the geopolymer from evaporating.

Figure 4. Liquid tote (left); hopper gun (right).
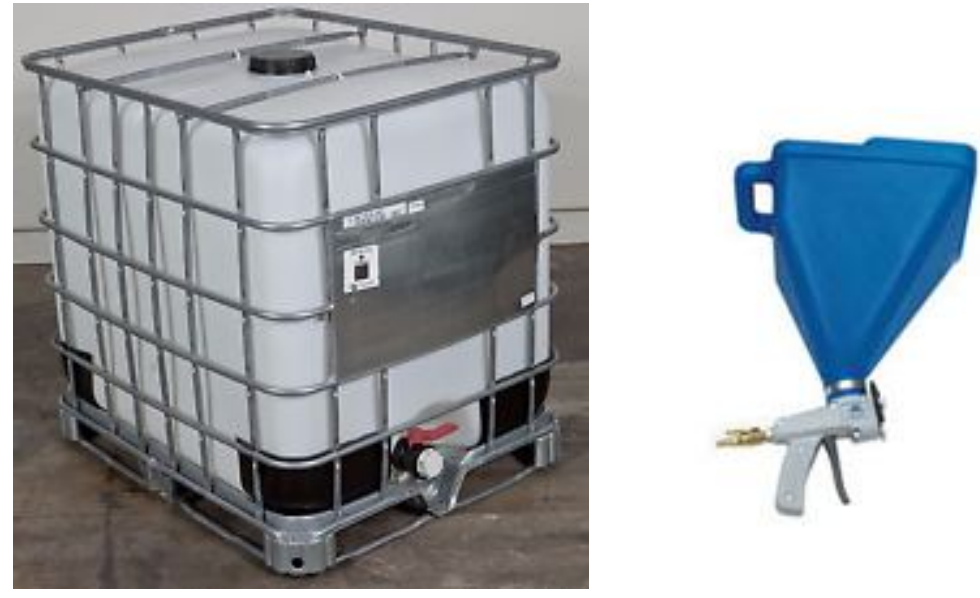

A similar methodology to the proposed method of construction is preplaced aggregate concrete (PAC), which is, detailed in a U.S. Army Corps of Engineers (USACE) Repair, Evaluation, Maintenance, and Rehabilitation (REMR) technical note (REMR CS-MR-9-4), a field guide from the American Concrete Institute Repair Application Procedure (ACI RAP-9), and a Unified Facilities Guide Specification (UFGS 0337 oo). The concept of PAC is not a new one; PAC has been used in industry for decades as a method of repairing structures as well as for several underwater construction applications (ACI RAP-9). PAC is defined as the production of structures by placing aggregate in a sealed form which is later injected with a binding mixture to fill the voids (ACI RAP-9). This method reduces shrinkage because of the high density of course aggregate and increase in pointto-point contact of large aggregate (REMR CS-MR-9-4).

The method described in this report deviates from the standard practice of preplaced aggregates, however. The proposed procedure is designed for horizontal application, not vertical, therefore the binder is applied to the 
top of the gradation and allowed to seep. Furthermore, the proposed method's binder is gravity fed, unlike the pressurized flow standard in PAC practice. Finally, the current work seeks to take the PAC practice a step beyond a repair procedure to a full pavement casting procedure. Future exploration into this proposed method of construction should consider applying the index of aggregate particle shape and texture (IAPST) and specific gravity relationships for total void content in order to proportion geopolymer mixtures with adequate stability and flowability, as in the work of Hendrix and Trejo (2017).

\subsection{Materials, Methods and Results}

Evaporation retardants that are commonly available in the market for OPC-based concrete were tested on geopolymers. It is important to note that none of manufacturers claimed their product would work for geopolymers. Geopolymer mortar was poured on small weigh boats, and the evaporation retardants were sprayed according to the standard practice prescribed by the manufacturer. Then the weigh boats were maintained at $21^{\circ} \mathrm{C}$ for 28 days. Their mass loss was measured as a function of time and then compared with a control sample that was sealed with a wet paper towel and maintained at $21^{\circ} \mathrm{C}$. The control lost the minimum amount of water, had a glossy surface finish, and exhibited the least amount of drying shrinkage to the naked eye when compared to all other samples. Therefore, it was concluded that the best way to use geopolymer in the field is to mimic the control run by covering the specimen with wet burlap to prevent water evaporation. The weight-loss curve is shown in Figure 5 .

Previous literature stated that conventional superplasticizers used in OPCbased concrete do not necessarily work well with geopolymers because of the difference in pH (Nematollahi 2014; Hardjito 2006; Vickers 2015). The high alkalinity of the sodium silicate solution leads to alkaline hydrolysis and Debye shielding, which renders the plasticizers ineffective (Puertas 2003). Hence, plasticizers were not used in this study. 
Figure 5. Mass $\%$ vs time of geopolymer mortar when coated with various commercially available evaporation retardants.

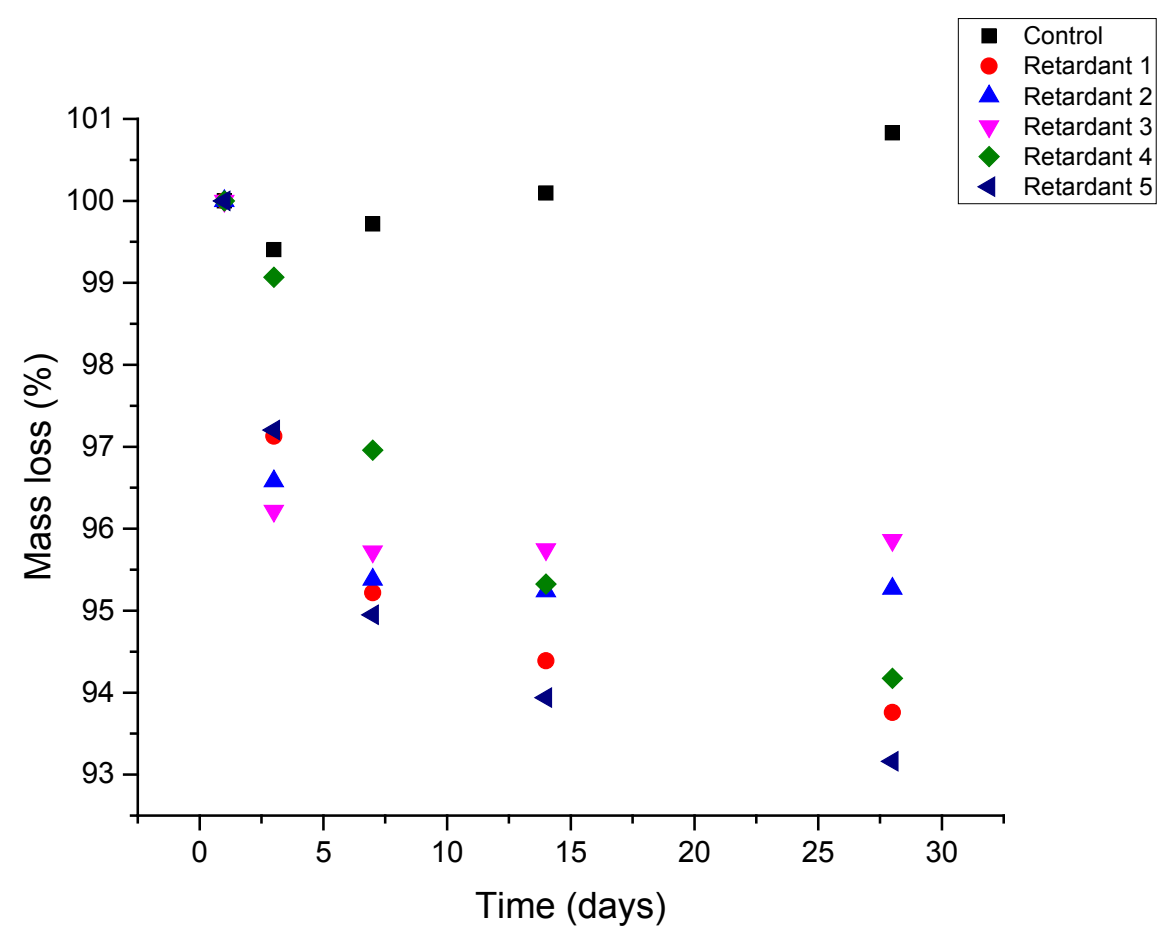

\subsection{Shrinkage testing}

For the geopolymer to find success in the field, it must hold up to the standard of durability set by Portland cement. One method of quantifying durability is by shrinkage resistance. Several geopolymer mixes where monitored by a comparator, according to procedures described in ASTM C596, in tandem with Portland cement mortar mixes in order to compare their relative shrinkage. The results are displayed in Figure 6. Geopolymer mortars cured in moist conditions performed similarly to Portland cement mortars in dry conditions. Geopolymer mortars cured in dry conditions after 7 days exhibited severe drying shrinkage, indicating the need for protection against evaporation. 
Figure 6. Strain due to drying shrinkage over time.

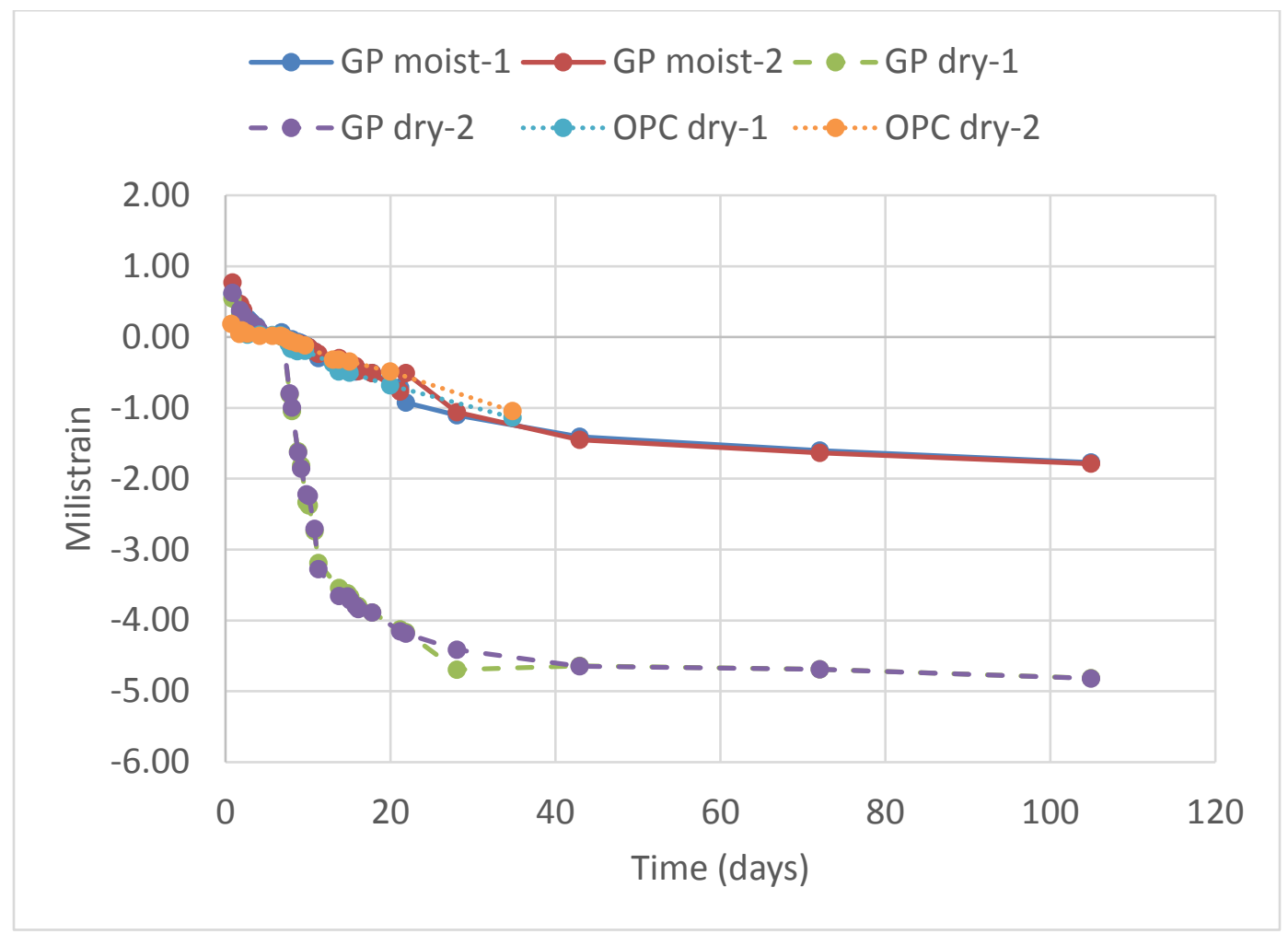

\subsection{Flow-rate analysis}

Flow-rate tests were performed to identify the ideal sand content to optimize cost, shrinkage, and seepage effectiveness. This test also helped to determine pot life of the geopolymer mixtures.

Three 4 in. diameter by 8 in. tall plastic cylinders were assembled. A single hole was drilled in the center of the base of each cylinder, and the cylinders were then labeled according to the hole size-either 1 in., $3 / 4$ in., or $1 / 2$ in. These holes were then plugged with rubber stoppers. One cylinder at a time was suspended above a data-logging scale which was electronically synced with a windows computer running compatible data collection software (Figure 7). Geopolymer was mixed and poured into the cylinder, and the mixing bowl was placed on the scale. Data collection was started and the rubber stopper removed, allowing the geopolymer to flow from the cylinder into the bowl below as the scale logged the mass gained at a frequency of 1 hertz. This process was repeated for the $3 / 4$ in. and $1 / 2$ in. cylinders sequentially, then data collection was stopped. This procedure was repeated every 10 minutes, until the mix no longer flowed. 
Figure 7. Active flow test setup.

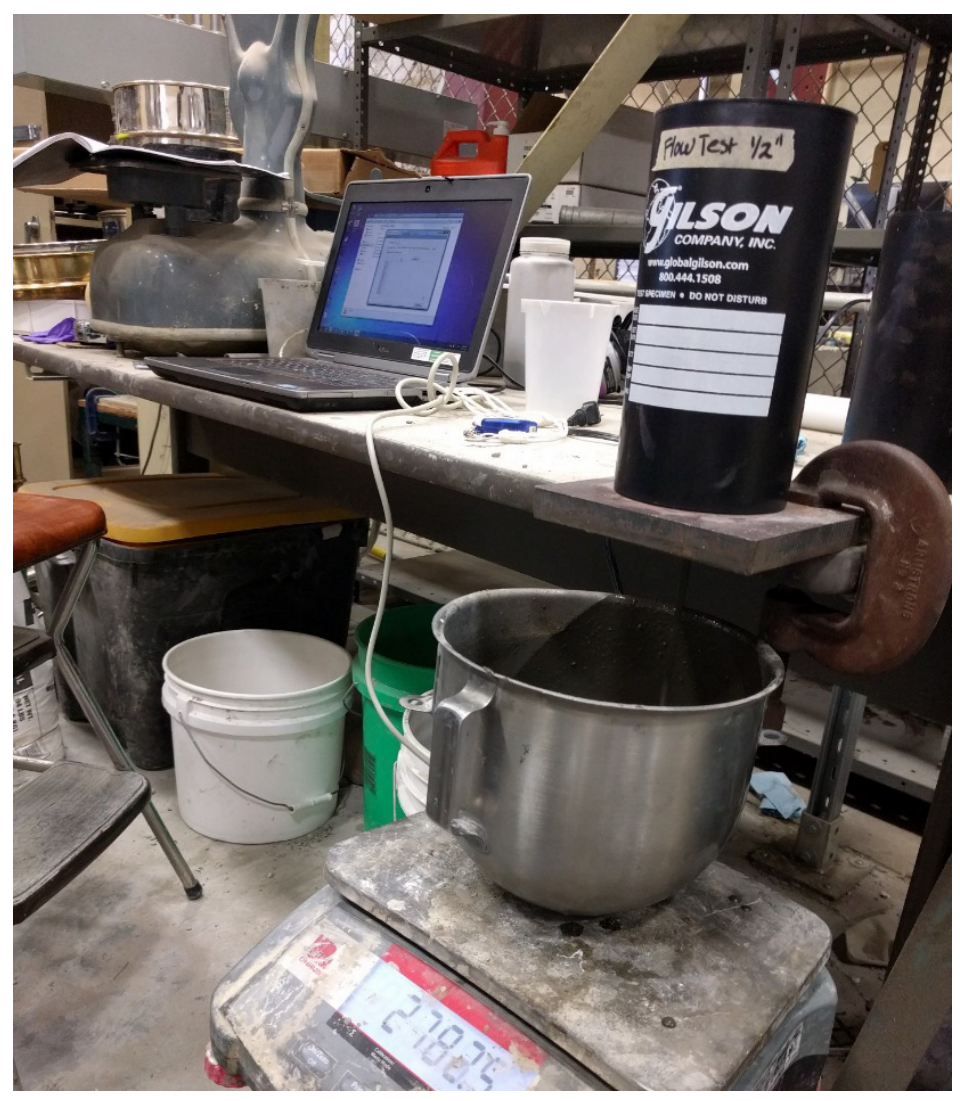

Before experimentally determining the flow rate, mathematical models were assessed in order to obtain a predicted range over which the true flow rates would likely fall. First, the incompressible Bernoulli equation was used to describe the flow of a low viscosity geopolymer mortar. Applying this equation to a "streamline" that starts at the top free surface and exits the spout (Figure 8) yields Equation 1.

$$
\begin{gathered}
\text { Equation } 1 . \\
p g z_{\text {surface }}+p_{\text {atm }}-\frac{1}{2} p V_{\text {jet }}^{2}+p g z_{\text {spout }}+p_{\text {atm }}
\end{gathered}
$$

Note that the exiting fluid jet experiences the same pressure as the free surface (patm). Solving for the fluid jet velocity gives Equation 2.

Equation 2.

$$
V_{\text {jet }}-\sqrt{2 g\left(z_{\text {surface }}-z_{\text {spout }}\right)}-\sqrt{2 g \Delta z}
$$

The non-zero viscosity of fluids will rob the flow of mechanical energy (converting it to heat within boundary layers hugging the spout walls); 
hence the fluid jet beyond the spout exit will have a slightly smaller diameter than the spout. This factor can be accounted for by a discharge coefficient $C$, whose value is typically between 0.90 and 0.98 . The volumetric flow-rate $Q$ results from multiplying the jet velocity times the cross-sectional area, as shown by Equation 3 .

\section{Equation 3.}

$$
Q=A_{\text {jet }} V_{\text {jet }}=C A_{\text {spout }} V_{\text {jet }}
$$

The setup as described above and shown in Figure 8 follows an unknown flow condition; therefore, the discharge coefficient $\mathrm{C}$ was back-calculated and found to be 0.10. Approximating the flow rates, we obtain Table 1.

Figure 8. Possible flow conditions.

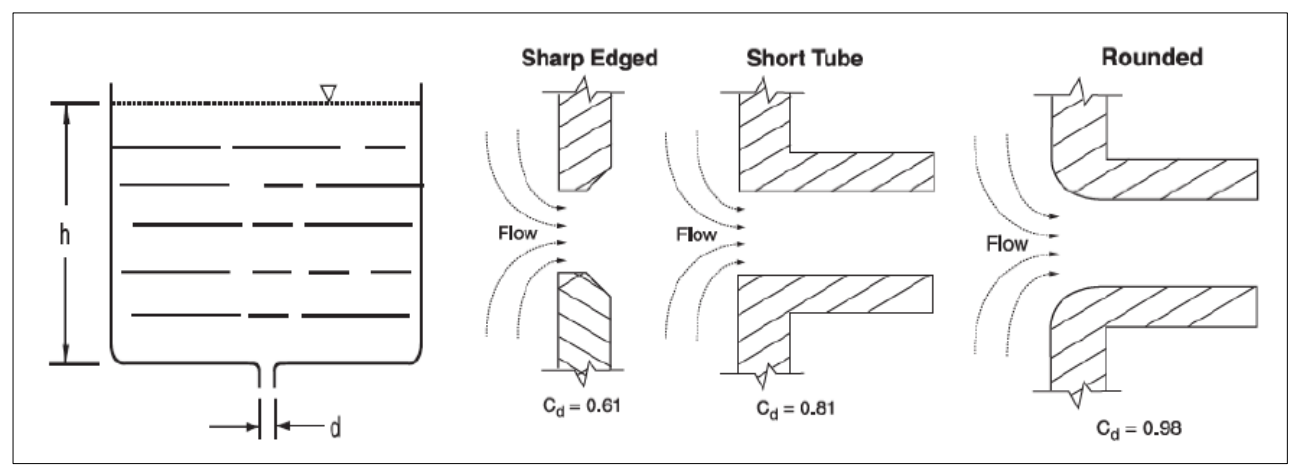

Table 1. Theoretical flow-rate calculation for $30 \%$ wt sand geopolymer mortar.

\begin{tabular}{|c|c|c|c|c|c|}
\hline $\begin{array}{c}\text { Hole diame- } \\
\text { ter }(\mathrm{d}) \text { in } \\
\text { inches }\end{array}$ & $\begin{array}{c}\text { Discharge } \\
\text { coefficient }\left(\mathrm{C}_{\mathrm{d}}\right)\end{array}$ & $\begin{array}{c}\text { Exit Velocity } \\
(\mathrm{m} / \mathrm{s})\end{array}$ & $\begin{array}{c}\text { Volume } \\
\text { flow rate } \\
(\mathrm{ml} / \mathrm{s}), \\
\left(\mathrm{in}^{3} / \mathrm{s}\right)\end{array}$ & $\begin{array}{c}\text { Mass flow } \\
\text { rate }(\mathrm{g} / \mathrm{s})\end{array}$ & $\begin{array}{c}\text { Density } \\
(\mathrm{g} / \mathrm{cm} 3)\end{array}$ \\
\hline 0.5 & 0.61 & 2.444 & $189,11.5$ & 68 & 2.010 \\
\hline 0.75 & 0.61 & 2.444 & $425,25.9$ & 153 & \\
\hline 1 & 0.61 & 2.444 & $755,46.41$ & 271 & \\
\hline
\end{tabular}

Next, the Navier-Stokes equation is applied to describe the flow of low viscosity geopolymer mortar, as shown in Equation 4.

\section{Equation 4.}

$$
\frac{d u}{d t}+(\boldsymbol{u} * \nabla) \boldsymbol{u}=-\frac{1}{p} \nabla \mathbf{P}+\boldsymbol{V}_{j e t} \nabla^{2} \boldsymbol{u}
$$


Solving for our system, we obtain Equation 5 .

\section{Equation 5.}

$$
V_{j e t}=2 \pi g h\left(\frac{1}{r_{2}^{2}}-\frac{1}{r_{1}^{2}}\right)^{-1}
$$

Calculating volumetric flow rate in a similar manner to that detailed above is shown in Equation 6.

\section{Equation 6.}

$$
Q=\frac{p g r^{2}}{8 u} A
$$

In Equation 6, $u$ is the viscosity of the mortar and $A$ is the area of the spout. This approximation is shown in Table 2.

Table 2. Theoretical volumetric flow rate of geopolymer mortar.

\begin{tabular}{|c|c|c|}
\hline $\begin{array}{c}\text { Sand Content, Density; } \\
\left.\text { [\%wt], [g/ml], [oz/in }{ }^{3}\right]\end{array}$ & Hole Diameter [in.] & $\begin{array}{c}\text { Volume Flow Rate } \\
{[\mathrm{ml} / \mathrm{s}],\left[\mathrm{in}^{3} / \mathrm{s}\right]}\end{array}$ \\
\hline \multirow{2}{*}{$35,2.19,1.27$} & 0.5 & $15,0.92$ \\
\cline { 2 - 3 } & 0.75 & $77,4.70$ \\
\hline \multirow{3}{*}{$45,2.07,1.19$} & 1 & $243,14.82$ \\
\cline { 2 - 3 } & 0.5 & $3,0.18$ \\
\cline { 2 - 3 } & 0.75 & $16,0.98$ \\
\hline \multirow{3}{*}{$454 \%$ added water, } & 1 & $51,3.11$ \\
\cline { 2 - 3 } $2.01,1.16$ & 0.5 & $25,1.53$ \\
\cline { 2 - 3 } & 0.75 & $127,7.75$ \\
\hline
\end{tabular}

Upon running the physical flow tests, there are consistently two regions of flow behavior found for each run-the first behavior being a linear region representing the steady state flow of geopolymer, and the second behavior being a power-law region which appears as the decrease in pressure becomes significant and flow slows or stops. Table 3 summarizes the experimentally determined volumetric flow rate of the geopolymer mortar during steady state flow. 
Table 3. Experimentally determined volumetric flow rate of geopolymer mortar.

\begin{tabular}{|c|c|c|}
\hline $\begin{array}{c}\text { Sand Content, Density; } \\
\text { [\%wt], [g/ml] }\end{array}$ & Hole Diameter [in.] & Volumetric Flow Rate [ml/s] \\
\hline \multirow{3}{*}{$35,2.19$} & 0.5 & 39.87 \\
\cline { 2 - 3 } & 0.75 & 123.91 \\
\cline { 2 - 3 } & 1 & 243.35 \\
\hline \multirow{3}{*}{$45,2.07$} & 0.5 & 20.66 \\
\cline { 2 - 3 } & 0.75 & 79.75 \\
\hline \multirow{3}{*}{$454 \%$ Added Water, } & 1 & 208.71 \\
\cline { 2 - 3 } 2.01 & 0.5 & 55.68 \\
\cline { 2 - 3 } & 0.75 & 112.27 \\
\hline
\end{tabular}

The end of the linear region is marked when either geopolymer runs out, as is evident from Figure 9 for the 1 in. diameter hole at 0 minutes for any mixture, or when the head pressure drops significantly. The $45 \%$ sand batches at 20 minutes express virtually zero flow in the $1 / 2$ in. hole, even with maximum head pressure. It is interesting to note that the definition of "significant head" changes as the geopolymer begins setting. This is likely caused by the increase in viscosity. According to the Bernoulli and Navier-Stokes equations, viscous material will resist flow much more strongly, therefore it is logical to attribute the decreasing flow rate, or in other words, the increase in pressure needed to maintain a flow rate to the rising viscosity during setting.

Rheological measurements were performed on these mixtures to determine the torque on a $1 \mathrm{in}$. diameter by $1.5 \mathrm{in}$. tall vane rotor at 8 minute intervals. In this way, a "flowable torque" can be obtained from the rheometer. The $45 \%$ sand mix through the $1 / 2$ in. hole is definitively unable to flow at 20 minutes. The corresponding torque at 16 minutes is 1.813 $\mathrm{mN}^{*} \mathrm{~m}$, and at 24 minutes is $1.852 \mathrm{mN}^{*} \mathrm{~m}$. The $35 \%$ sand mortar was last seen flowing at $0.816 \mathrm{mN}^{*} \mathrm{~m}$, and the $45 \%$ sand mortar with added water last flowed at $0.512 \mathrm{mN}^{*} \mathrm{~m}$. The mortars with $35 \%$ sand and $45 \%$ sand with added water remained flowable until initial set occurred. The $35 \%$ sand mortar showed the longest "pourable lifetime," being pourable at a maxi- 
mum of 40-50 minutes (Figure 9). Based on these results, we find that geopolymer will not flow through a hole beyond such time as the torque measured by the rheometer with a $1 \mathrm{in} . \mathrm{x} 1.5 \mathrm{in}$. vane rotor is approximately 1.0 to $1.5 \mathrm{mN}^{*} \mathrm{~m}$.

Based on the overall results in this section, for gravity-fed delivery systems, the use of a 3/4-in. diameter hole and geopolymer mortar with 35 \%wt sand is recommended.

Figure 9. Flow comparison over time, with spout diameters of 1 in. (top), $3 / 4$ in. (middle), and $1 / 2$ in. (bottom).

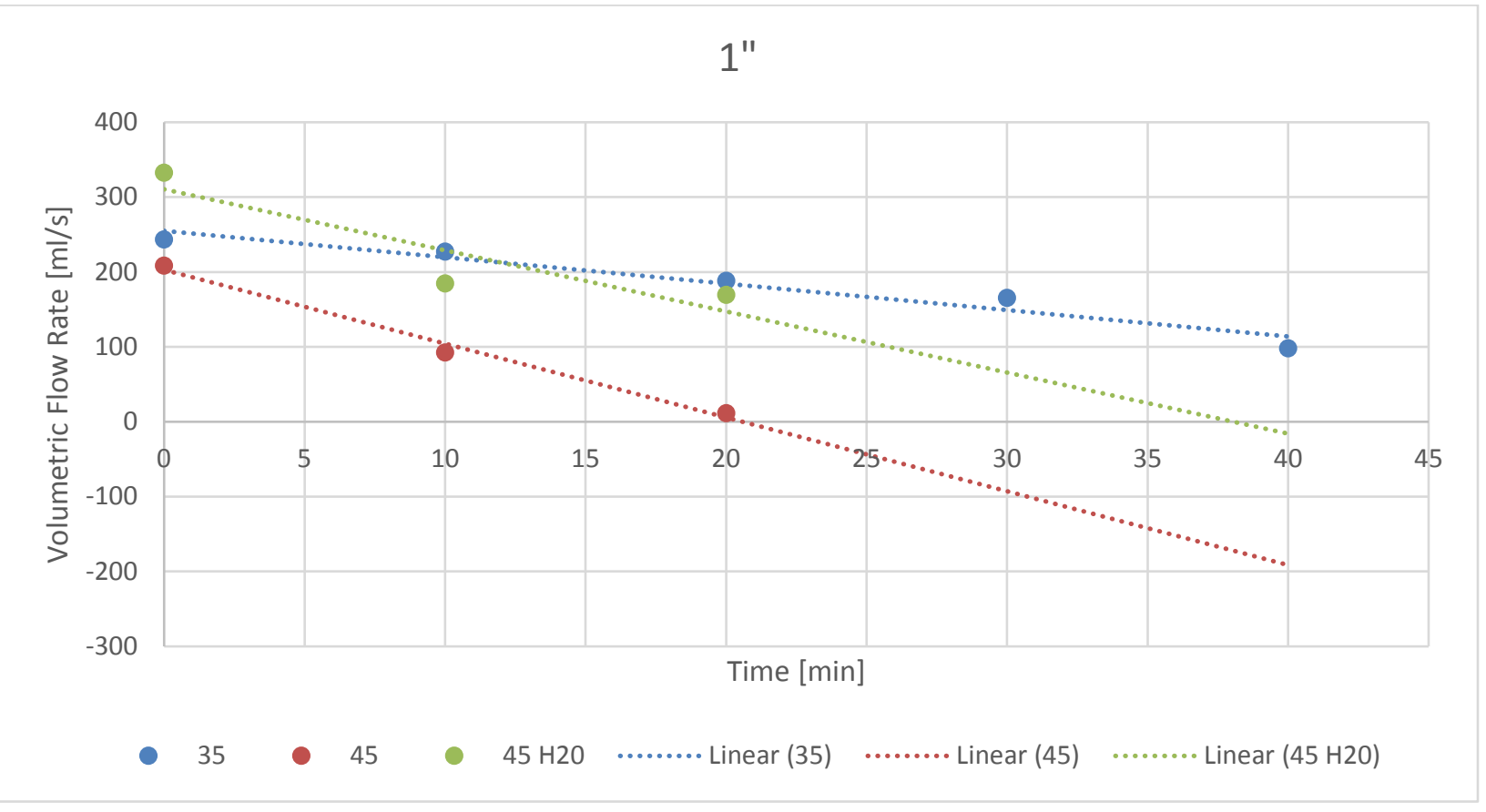



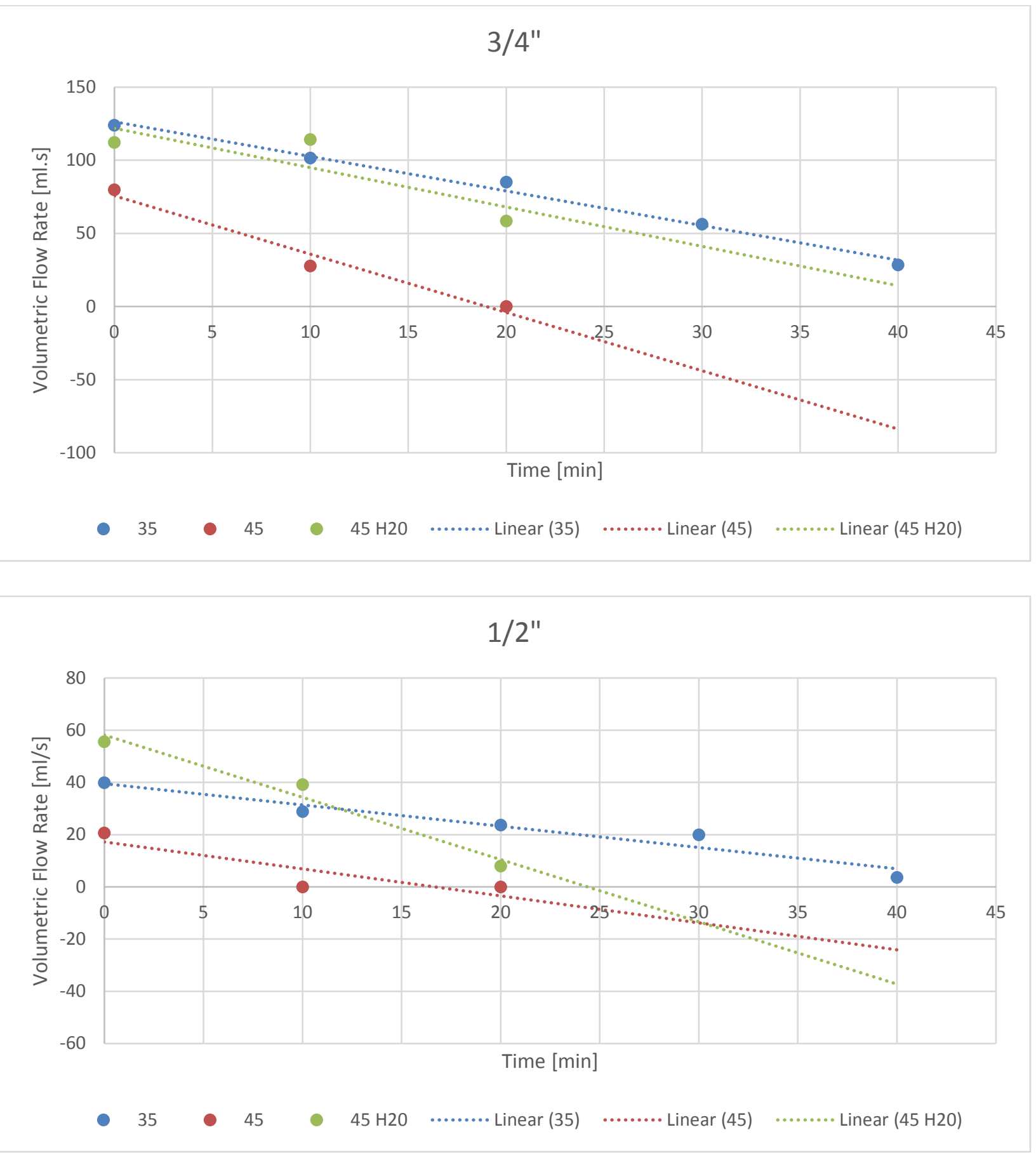

A graphical comparison to the two mathematical predictions indicates that the geopolymer follows Navier-Stokes equations for incompressible liquids, and the Bernoulli equation is too idealized for the complexities of granular flow. Figure 10 clearly shows that the $35 \%$ mortar fits between the two approximations, though more closely to Navier-Stokes. The $45 \%$ and $45 \%$ with added water mortars were not estimated via Bernoulli and 
are therefore not shown; they do, however, follow closely the NavierStokes approximation, as seen in Table 2 and Table 3.

Figure 10. Comparison of mathematical prediction to experimental data.

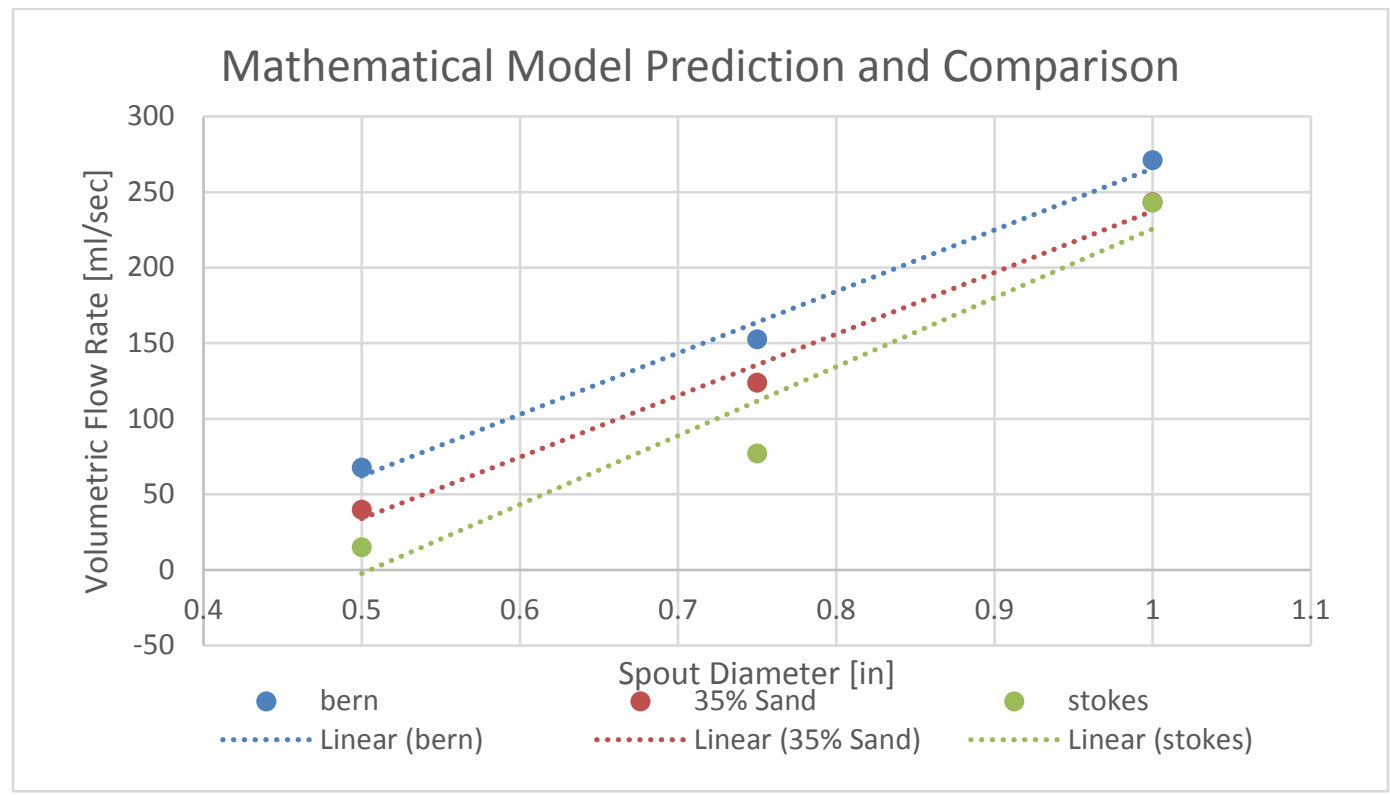

\subsection{Sand and gravel characterization}

It is pertinent to understand the characteristics of the gradations of the base course used for the test pavements and the sand used for the mortar. Figure 11 illustrates the visual difference in gradation between the base course and ASTM \#67 gravel. Void testing was performed on pea gravel and ASTM \# 6 and \#67 gradations by weighing water which filled a gravel bed in a bucket to a specified level (Figure 12). Knowing the void content allows for accurate determination of the volume of geopolymer per volume of surface course and, in the case of the test pavements, allows the prediction of which gradation will have the best percolation qualities. Figure 13 summarizes the void test results. 
Figure 11. Base course (left); approximate \#67 gradation (right).

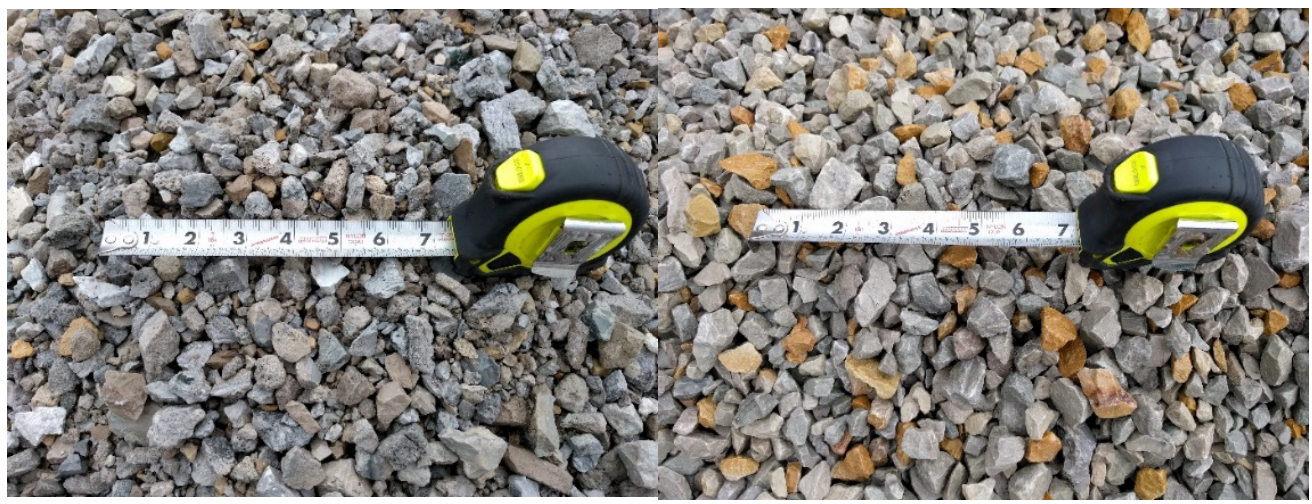

Figure 12. Void test side view (left); birds-eye view (right).

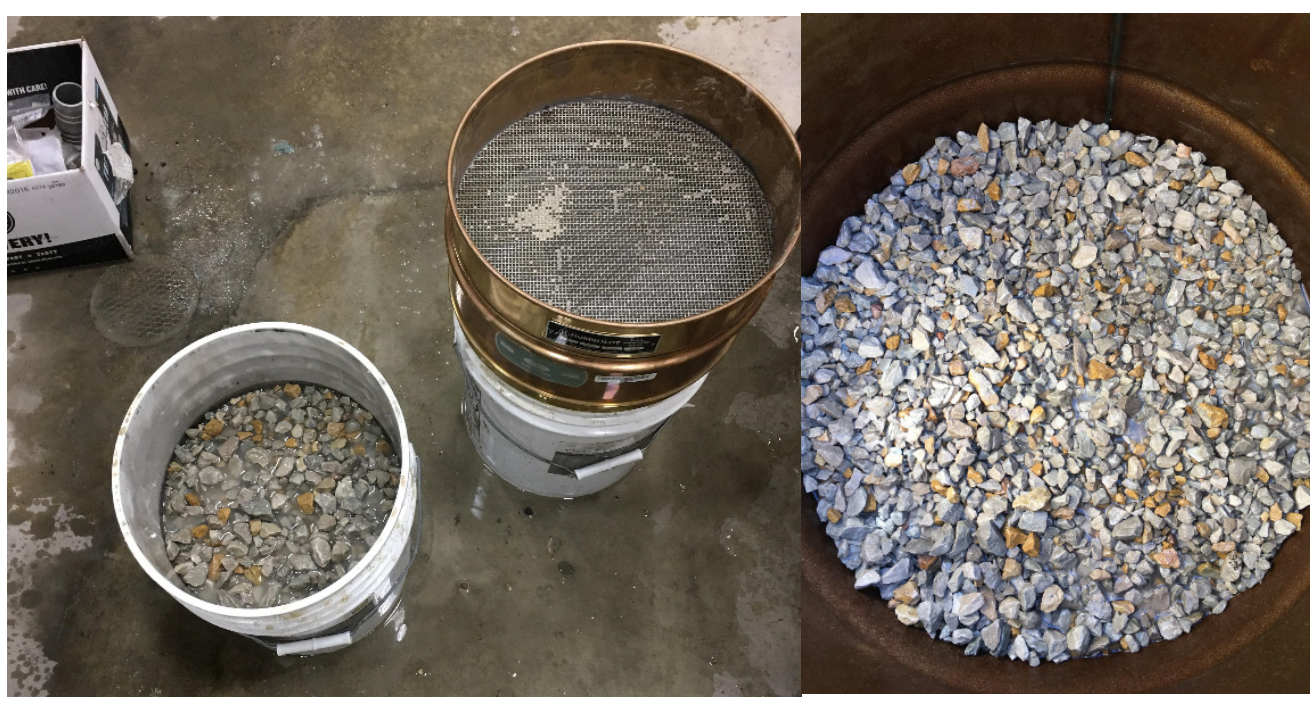

Figure 13. Void content of gradations measured by mass of water fill.

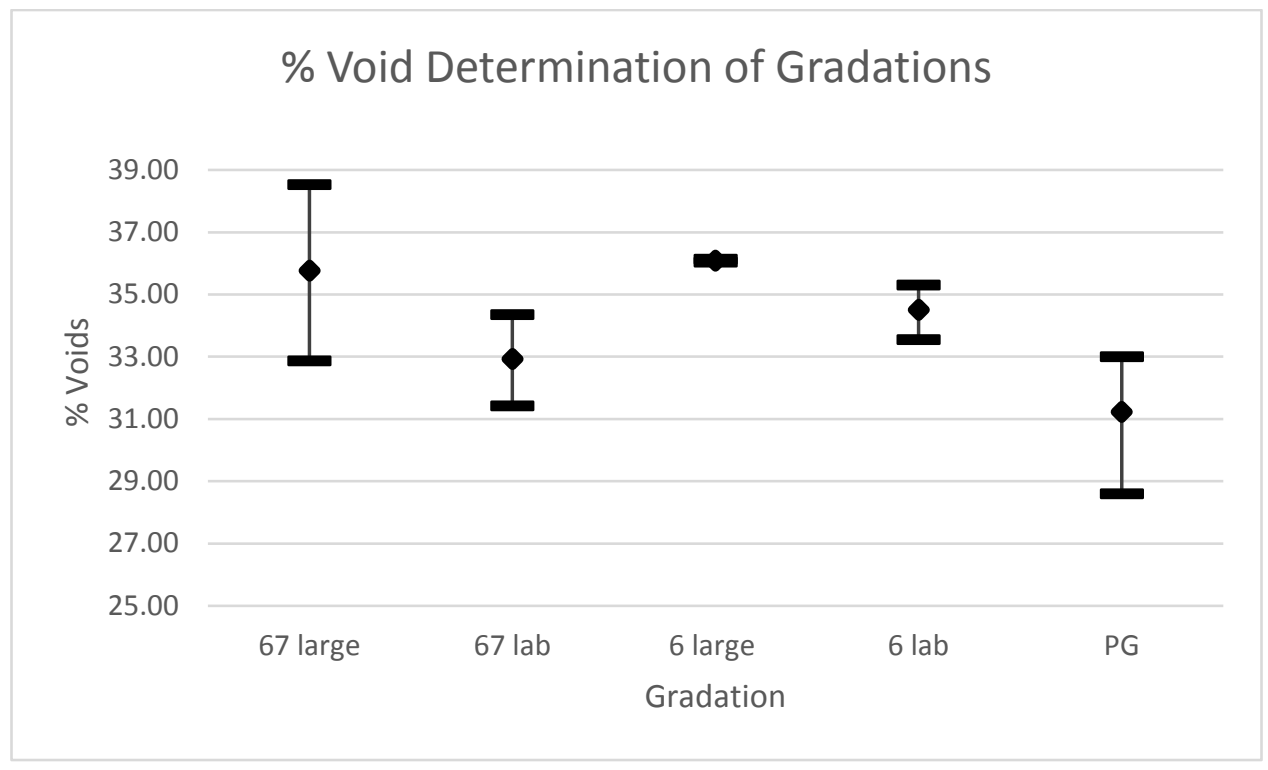


The sand gradation was carried out in compliance with ASTM C778 using 12 in. diameter sieve stacks in a sieve shaker. US No. 16, 30, 40, 50, and 100 sieves were used. The respective millimeter opening size in each of these sieves is $1.18 \mathrm{~mm}, .595 \mathrm{~mm}, .400 \mathrm{~mm}, .300 \mathrm{~mm}$, and $.149 \mathrm{~mm}$. Approximately 2,000 grams of sand was poured onto the top of the stack. A lid was placed on top of the stack, and the machine was allowed to shake for approximately two minutes. This procedure was repeated for three trials, as seen below in Table 4 and Figure 14. The pavements constructed from geopolymer mortar mixtures and gravel bed using these aggregates revealed the $35 \%$ sand mortar and $45 \%$ sand mortar with added water had similar seepage properties. The $45 \%$ sand mortar with added water, however, had decreased load-bearing capabilities. Plain $45 \%$ sand was not tested in this manner. Ultimately, the $35 \%$ sand mixture constructed the strongest and most fully percolated pavements.

Table 4. Sand gradation fineness modulus.

\begin{tabular}{|c|c|c|c|}
\hline & Trial 1 & Trial 2 & Trial 3 \\
\hline Fineness Modulus & 2.612 & 2.575 & 2.693 \\
\hline
\end{tabular}

Figure 14. Sand grain size distribution.

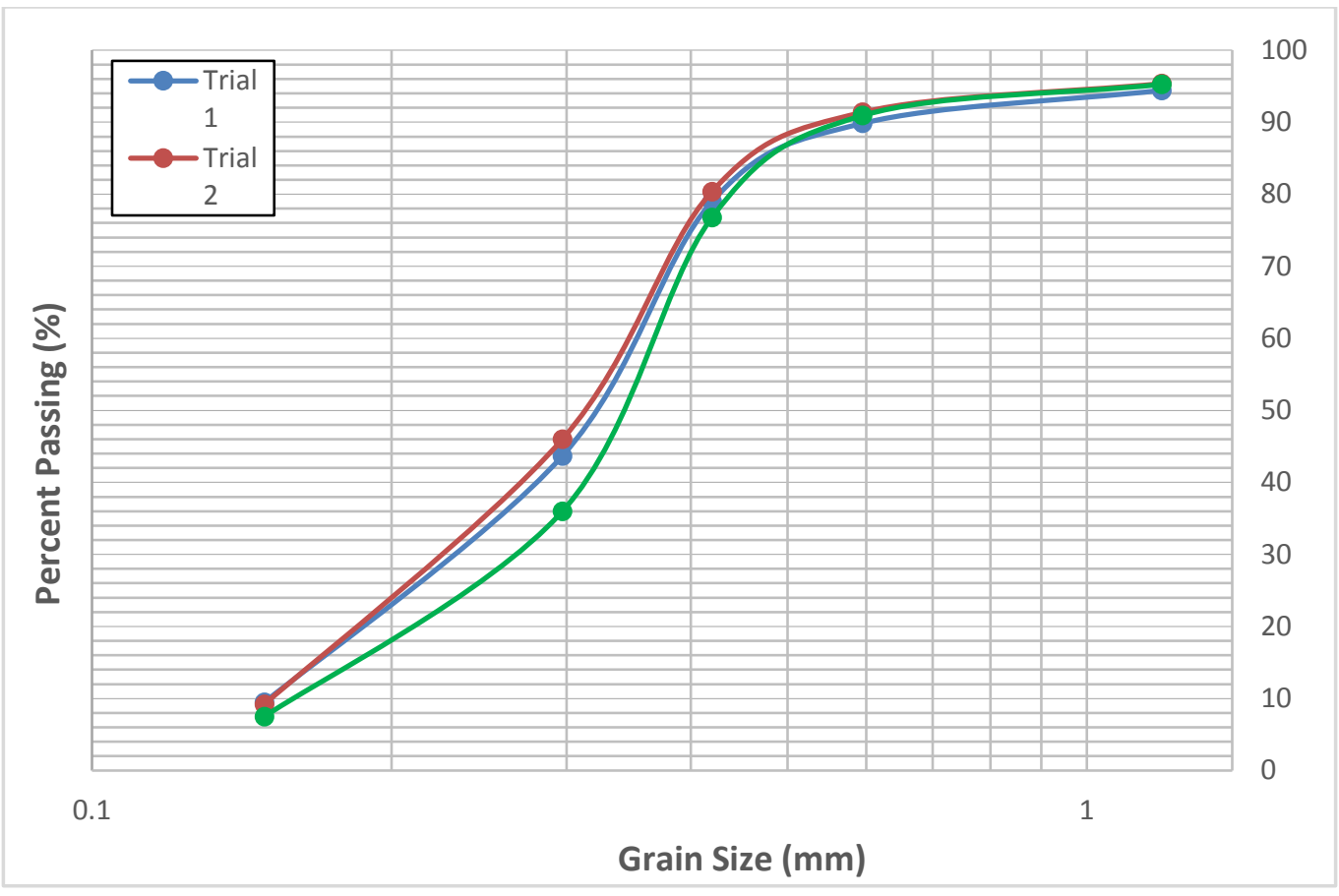




\subsection{Test pavement}

As previously stated, the surface course of the pavement will be prepared by pouring a geopolymer mortar over a coarse gravel bed. It is essential to calculate or measure the void fraction in the coarse aggregate bed and select a fine aggregate loading in geopolymer. After the geopolymer set in the test pavement, cross sections of the pavement were examined for void content and extent of seepage through the base course, if any. The compressive strengths of the cores taken from the surface course were determined.

A wooden box was constructed such that ten small "test pavements" could be laid inside (Figure 15). Each box-within-the-box was 22 in. $x 18$ in. The separating beams and perimeter were constructed from 2x8 and 2x10 lumber, and the base was plywood. Road-pack base course was laid in each box and compacted with a jack tamper. Varying gradations of gravel were then laid on top the road pack and, if required, tamped with a $12 \times 12$ in. hand tamper. These gradations were put in place on the same day the geopolymer was to be poured. Geopolymer mortar was prepared in a paddle mixer and poured over the gradations slowly, starting in the corner and working toward the middle (Figure 16). As described in earlier sections, each box was filled in two lifts to allow the geopolymer to adequately percolate. Holes were drilled in the sides of the boxes to prevent airlock and to further facilitate seepage. The pavers were smoothed with a trowel and covered with a tarp to maintain moisture content.

Figure 15. Test plan (left); boxes 1-3 filled, boxes 4-10 show compacted base course.

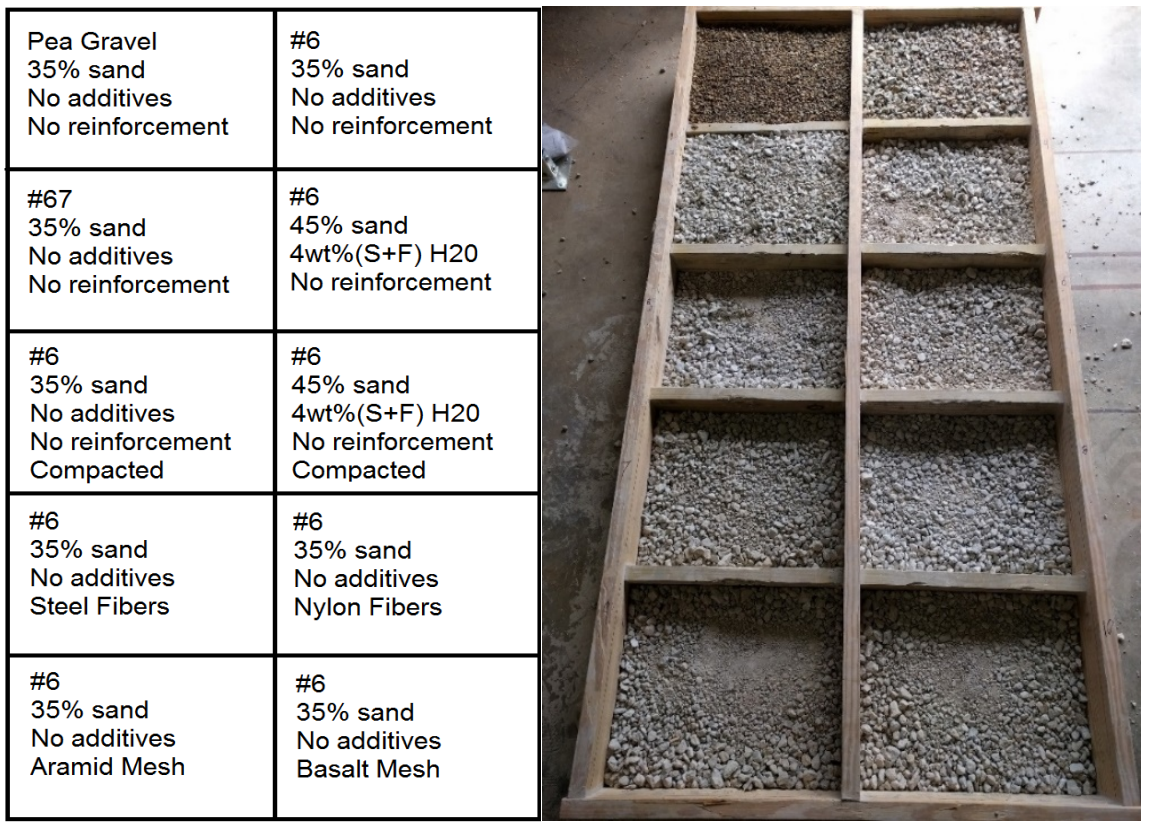


Figure 16. Initial pour starting in the corner (left), and working inward (right).

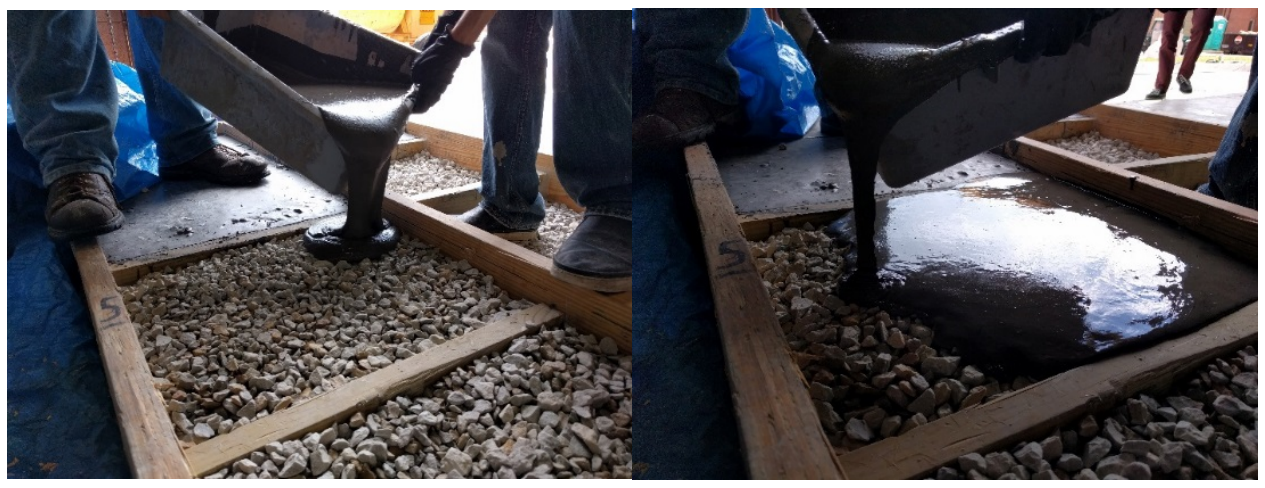

Cylinders and beams were cut from the test pavers (Figure 17). Only one cylinder was cut per test date and per pavement type, such that three cylinders were cut from each pavement. The section of pavement where the cylinders were bored was cut off, leaving a rectangle of paver behind. Beams were then cut and smoothed to obtain rectangular prisms for bending tests. Cylinders were crushed according to ASTM C109 via a hydraulic compression machine at 7,14 , and 28 days at $200 \mathrm{lb} / \mathrm{s}$. Beams were subjected to 3-point bend testing on a test frame on day 28 according to a modified ASTM C293 procedure (Figure 18). Due to some beams experiencing less than $100 \%$ seepage, the bottoms were inconsistent between samples and often jagged or uneven; therefore, to test the flexural strength, the beams were oriented such that the load was applied on the cut faces, not the top and bottom of the pavement. For each box (refer to Figure 15), four to eight beams were cut and successfully tested (Figure 19). 
Figure 17. Cutting cores (top left); Core compilation (top right); box with half the pavements cored and half removed (bottom).

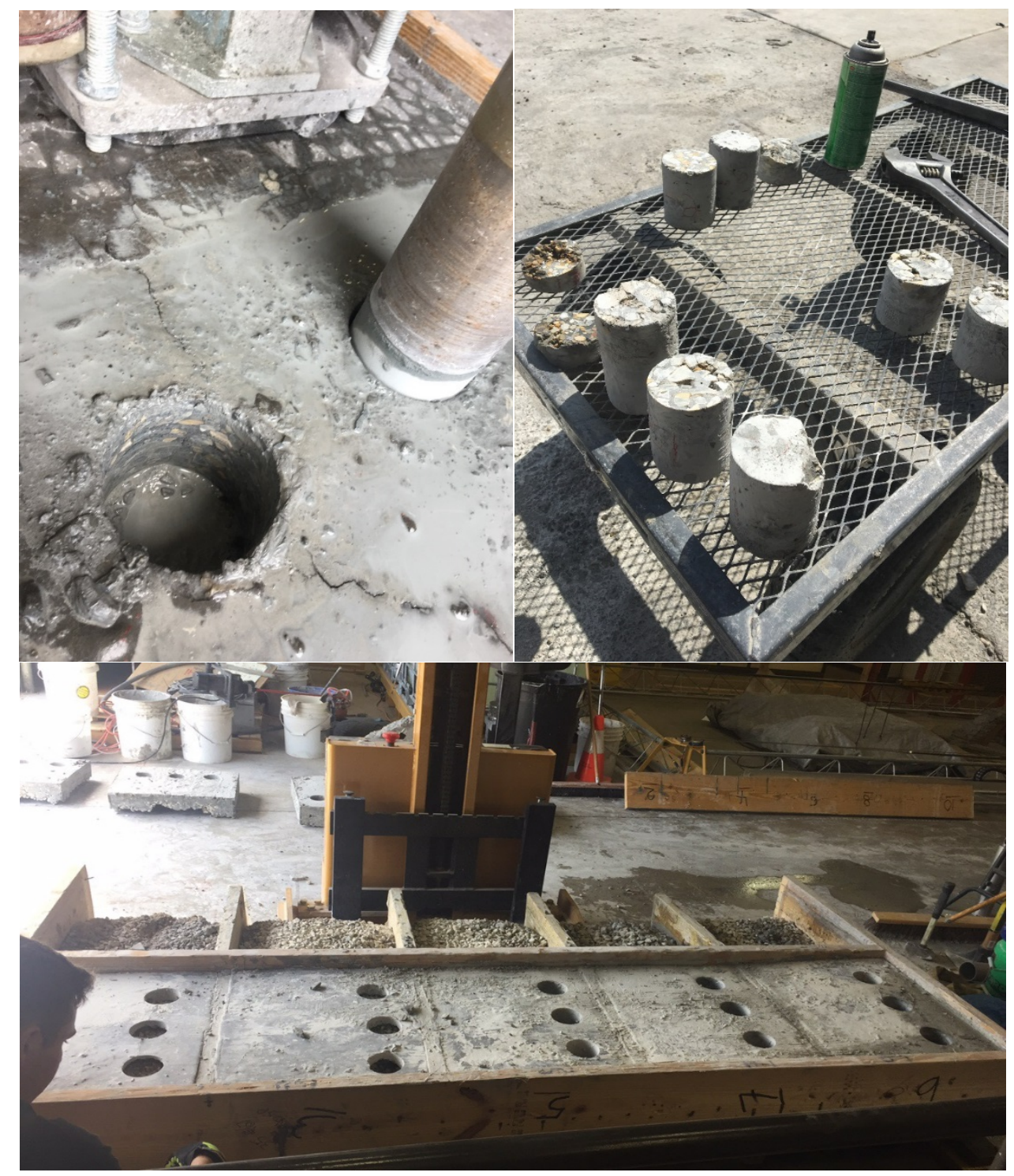


Figure 18. Showing the 3-point bend test (left); compression test (right).

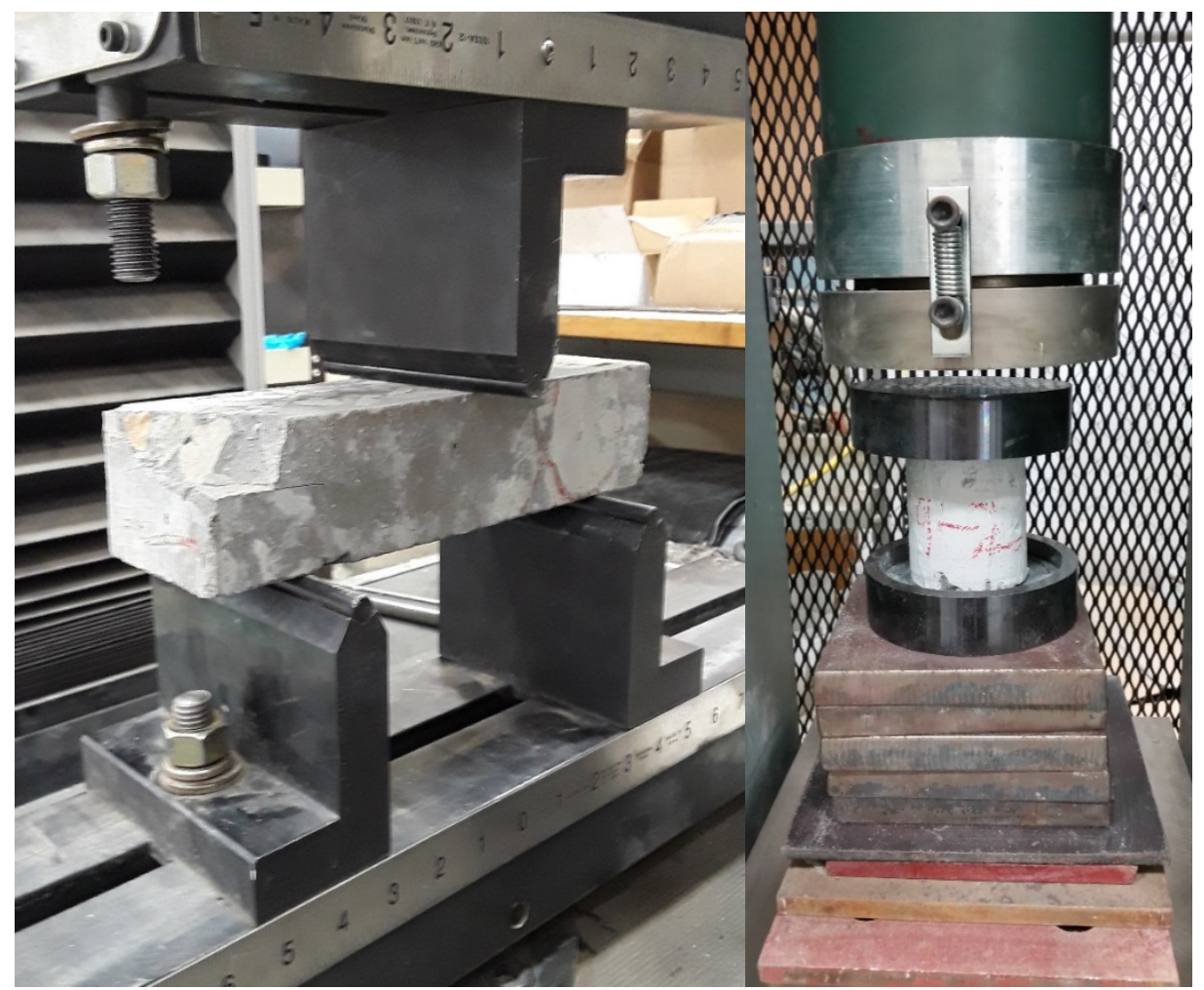


Figure 19. Fractured beams (top); crushed cylinders (bottom).

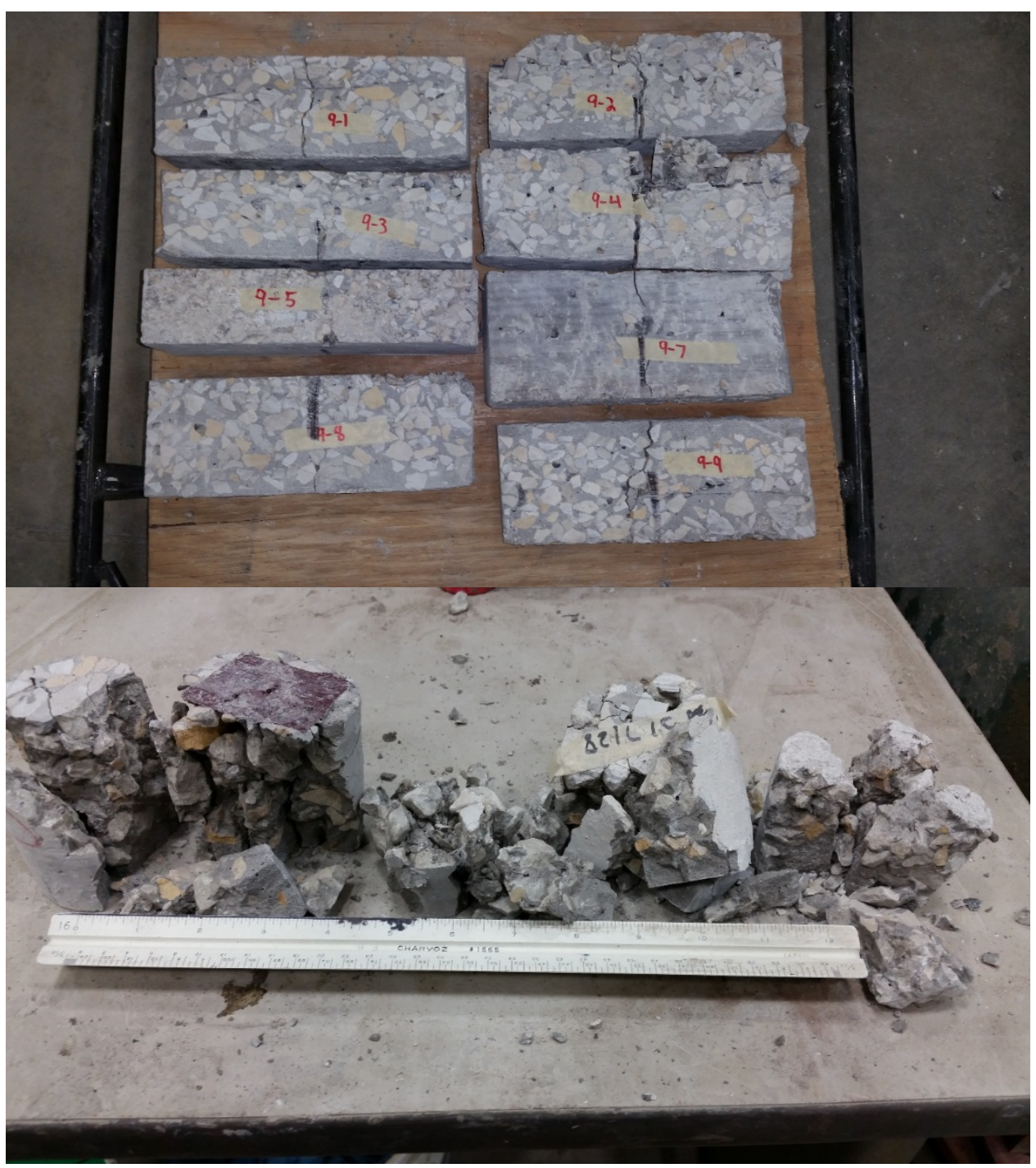

Figure 20 summarizes the results of the geopolymer core compressive strength tests. The degree of seepage varied from pavement to pavement due to mix design and additives, ultimately resulting in different heights between cores. The effect of the height variation is most evident in pavements 1 and 3, which saw little seepage resulting in a low height to diameter ratio and high strength, and pavement 8 , which saw uneven seepage resulting in a single low ratio core which was tested at 14 days. 
Figure 20. Core compression test results.

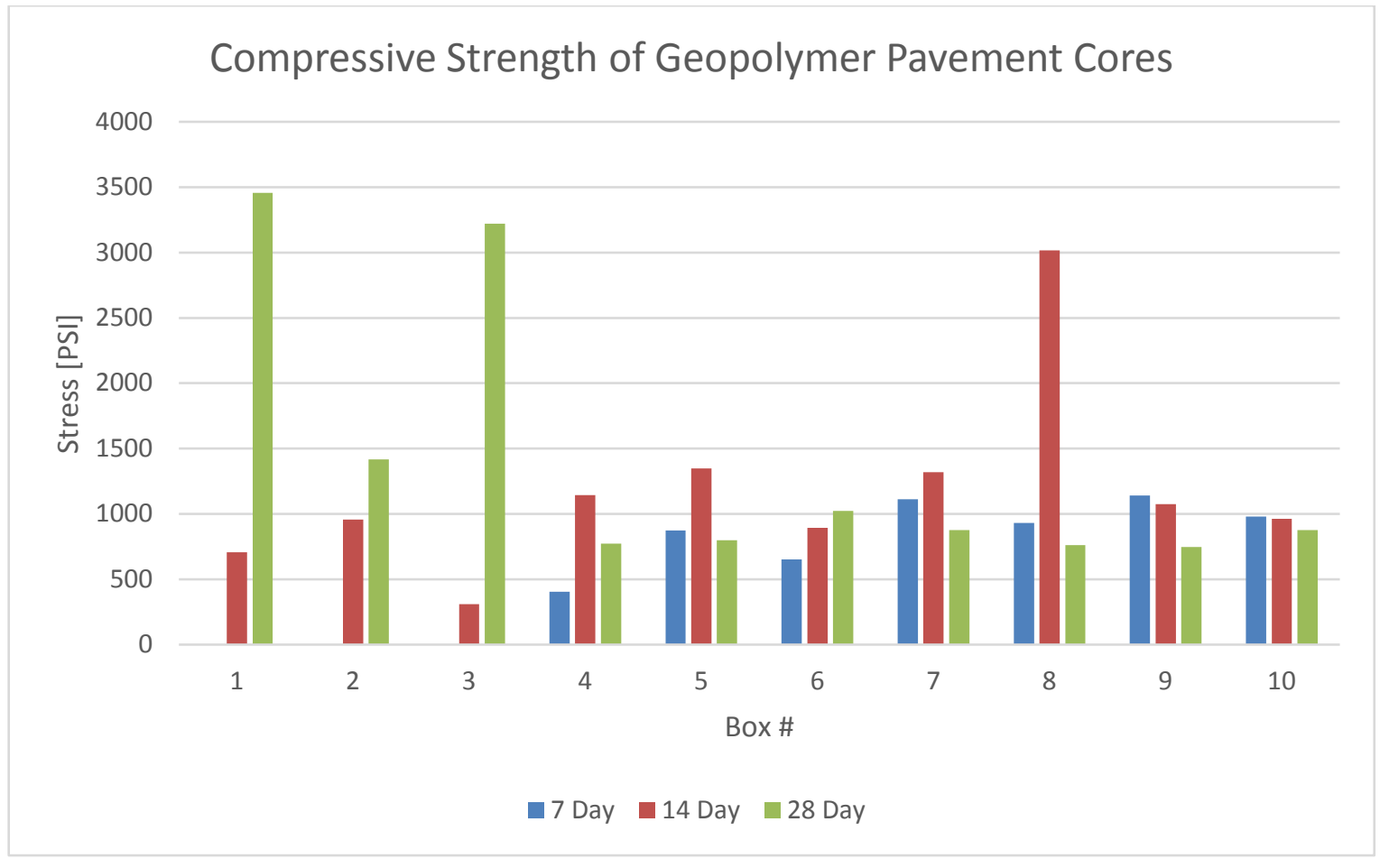

It is difficult to determine which combination of sand and reinforcement is best from the compression tests due to the large variation in core heights. Therefore, the beam tests were critical to the analysis of the test pavements. Figure 21 shows that pavements containing \#6 gravel bed with no reinforcement (box 2 in Figure 15) performed optimally under flexural loading, which adds clarity to the scattered compression data in Figure 20.

Figure 21. Beam 3-point bend test results.

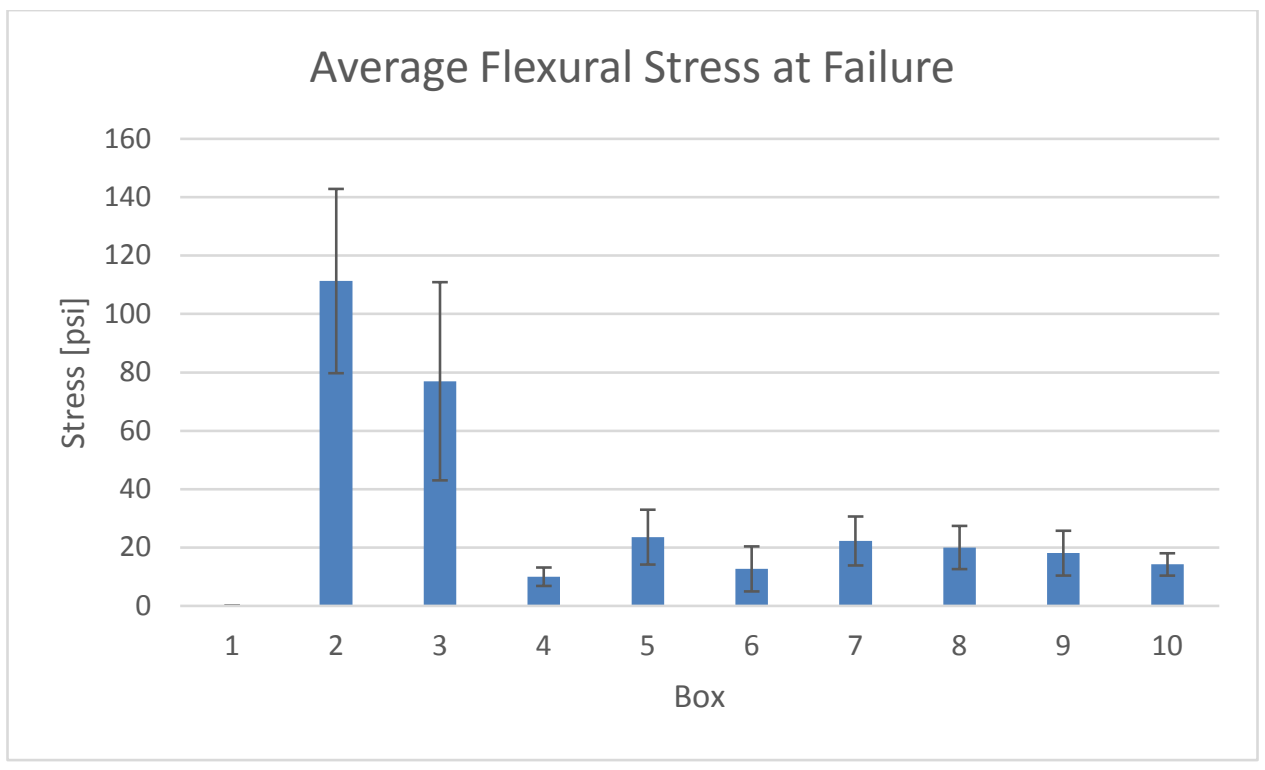




\section{Conclusion}

The current method of construction of concrete pavements and hard stands is costly, inefficient, and requires highly specialized equipment. A new method of construction utilizing geopolymers and gravel beds is proposed to address these issues, with the ultimate goal of streamlining the construction process.

To limit moisture loss, we considered the effect of evaporation retardant admixtures. We found it is best to have no additive, and instead to cover the geopolymer with plastic or moist burlap to prevent moisture loss. Future work must address drying shrinkage by means of expansion joints if there is no available moisture loss inhibitor. Considering the new construction method, the viscosity and flow of the geopolymer mortar are crucial components in the success of the technique. Flow testing revealed that water is an effective flow enabler and the geopolymer follows NavierStokes flow model predictions. It is recommended to use $35 \%$ wt sand, with a fineness modulus between 2.4 to 2.8 to maintain confidence that the geopolymer will fully percolate to the base course, while also minimizing the water required in the mixture. In addition to flow properties, the gravel bed gradation void content is a second factor which affects the percolation of the geopolymer. The test pavements showed that pea gravel and ASTM \#67 gradation are ineffective at facilitating seepage and should not be used in pavement construction. ASTM \# 6 gradation with $33 \%-37 \%$ voids was found to work well. The resulting pavement can withstand compression forces and successfully resist bending. Note that results from plasticizer and rheology testing will appear in a peer-reviewed publication to be submitted in late 2017 .

For future construction of geopolymer infrastructure, it is pertinent that the mortar contains $35 \%$ sand content over an ASTM \#6 gradation to ensure seepage of the geopolymer mixture to the base course and high compressive strength. During cure time, the geopolymer must be covered with plastic or wet burlap to minimize loss of moisture and shrinkage cracking. It is possible that expansion joints may accommodate long-range shrinkage issues. 


\section{References}

ACI RAP-9, 2010. "Spall Repair by the Preplaced Aggregate Method.” In Field Guide to Concrete Repair Application Procedures. Farmington Hills, MI: American Concrete Institute (ACI).

Al-Chaar, Ghassan K., Peter B. Stynoski, Kaushik Sankar, Marion L. Banko, Waltraud M. Kriven, and Imad L. Al-Qadi. 2017. Development and Testing of Geopolymers for Soil Stabilization on Military Installations. Technical Report ERDC/CERL TR17-9. Champaign, IL: Engineer Research \& Development Center, Construction Engineering Research Laboratory.

ASTM C33. 2016. Standard Specification for Concrete Aggregates. West Conshohocken, PA: ASTM International.

ASTM C109. 2016. Standard Test Method for Compressive Strength of Hydraulic Cement Mortars (Using 2-in. or [50-mm] Cube Specimens). West Conshohocken, PA: ASTM International.

ASTM C293. 2016. Standard Test Method for Flexural Strength of Concrete (Using Simple Beam with Center-Point Loading. West Conshohocken, PA: ASTM International.

ASTM C596. 2017. Standard Test Method for Drying Shrinkage of Mortar Containing Hydraulic Cement. West Conshohocken, PA: ASTM International.

ASTM C778. 2017. Standard Specification for Standard Sand. West Conshohocken, PA: ASTM International.

Bruce, M.E.C., R.R. Berg, J.G. Collin, G.M. Filz, M. Terashi, and D.S. Yang. 2013. Federal Highway Administration Design Manual: Deep Mixing for Embankment and Foundation Support. Washington, DC: U.S. Federal Highway Administration of U.S. Department of Transportation.

Davidovits, J. 2008. Geopolymer Chemistry and Applications. Saint Quentin, France: Geopolymer Institute.

Glasby, T., J. Day, R. Genrich, and J. Aldred. 2015. "EFC Geopolymer Concrete Aircraft Pavements at Brisbane West Wellcamp Airport.” Concrete 2015 Conference. Melbourne Australia. 1-9.

Hardjito, D., and B.V. Rangan. 2006. "Development of Fly Ash-Based Geopolymer Concrete: Progress and Research Needs.” ACI Materials Journal 101 (6): 467472.

Hayward Baker Inc. 2012. "Dry Soil Mixing." http://www.haywardbaker.com/solutions/techniques/dry-soil-mixing.

Hendrix, Greg, and David Trejo. 2017. "New Mixture Proportioning Method for Flowing Concrete Mixtures.” ACI Materials Journal 114(4): 507-516. 
Keller Inc. 2011. "Improvement of Weak Soils by the Deep Soil Mixing Method." Keller Brochure 32-01E. http://keller-foundations.co.uk/technique/deep-dry-soilmixing.

Makusa, Gregory P. 2012. "Soil Stabilization Methods and Materials: In Engineering Practice." State of the Art Review in Engineering Practice. Lulea, Sweden: Department of Civil Engineering and Natural Resources Engineering, Division of Mining and Geotechnical Engineering, Lulea University of Technology.

Massarsch, K.R., and M. Topolnicki. 2005. "Regional Report: European Practice of Soil Mixing Technology.” In Proceedings, International Conference on Deep Mixing, R19-R45. Stockholm.

Nematollahi, Behzad, and Jay Sanjayan. 2014. "Efficacy of Available Superplasticizers on Geopolymers." Research Journal of Applied Science \& Engineering Technology 7(7): 1278-1282.

Puertas, F., A. Palomo, A. Fernandez-Jimenez, J.D. Izquierdo, and M.L. Granizo. 2003. "Effect of Superplasticisers on the Behaviour and Properties of Alkaline Cements." Advances in Cement Research 15 (1): 23-28.

REMR TN CS-MR-9.4. 1992. "Specialized Repair Technique Preplaced-Aggregate Method.” Washington, DC: U.S. Army Corps of Engineers-Repair, Evaluation, Maintenance, and Rehabilitation (REMR) Research Program.

Rogers, C.D.F, and S. Glendinning. 1996. "Modification of Clay Soils Using Lime.” In Lime Stabilisation, 99-112. Online publication: Thomas Telford Services Ltd.

Stab, E.B. 2002. "Development of Design and Construction Methods to Stabilize Soft Organic Soils: Design Guide for Soft Soil Stabilization.” CT97-0351. Brussels, Belgium: European Comm. Ind. Mater. Technol. Program (Rite-EuRam III).

UFGS (Unified Facilities Guide Specification) 0337 00. 2009. Preplaced-Aggregate Concrete. (In Division o3 - Concrete). Washington, DC: Department of Defense.

Vickers, L., A. van Riessen, and W.D.A. Rickard. 2015. Fire-Resistant Geopolymers: Role of Fibres and Fillers to Enhance Thermal Properties. Singapore: Springer.

Wagners. 2014. Brisbane West Wellcamp Airport. http://www.wagner.com.au/main/ourprojects/brisbane-west-wellcamp-airport. 


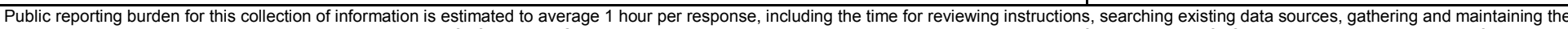

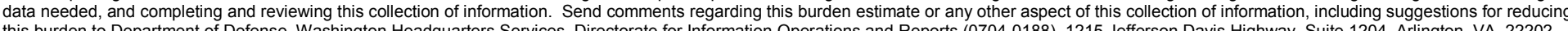

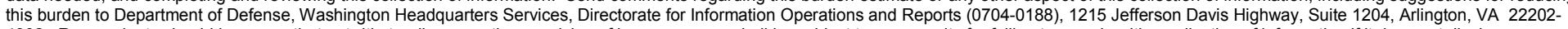

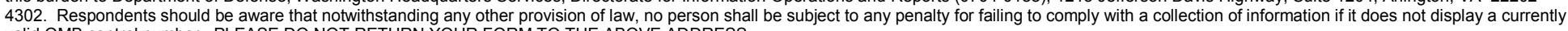
valid OMB control number. PLEASE DO NOT RETURN YOUR FORM TO THE ABOVE ADDRESS.
1. REPORT DATE (DD-MM-YYYY)
December 2017

\section{REPORT TYPE}
Final Technical Report
3. DATES COVERED (From - To)

\section{TITLE AND SUBTITLE}

Method of Construction for Geopolymer Soil Stabilized Platforms

5a. CONTRACT NUMBER

5b. GRANT NUMBER

5c. PROGRAM ELEMENT NUMBER

6. AUTHOR(S)

Ghassan K. Al-Chaar, Peter B. Stynoski, Matthew M. Landi, and Marion L. Banko

\section{5d. PROJECT NUMBER}

461088

5e. TASK NUMBER

\section{5f. WORK UNIT NUMBER}

8. PERFORMING ORGANIZATION REPORT NUMBER

ERDC/CERL TR-17-44
U.S. Army Engineer Research and Development Center (ERDC)

Construction Engineering Research Laboratory (CERL)

PO Box 9005

Champaign, IL 61826-9005

\section{SPONSORING / MONITORING AGENCY NAME(S) AND ADDRESS(ES)}

Headquarters

US Army Corps of Engineers

441 G Street NW

Washington DC 20314-1000

12. DISTRIBUTION / AVAILABILITY STATEMENT

Approved for public release. Distribution is unlimited.

\section{SUPPLEMENTARY NOTES}

\section{ABSTRACT}

To protect valuable assets from corrosive environments and associated maintenance issues, the Department of Defense (DoD) military services prefer to store vehicles, aircraft, and equipment in controlled environments, such as engineered tension fabric structures. However, this type of structure requires a solid base, which is often made of concrete and when left behind, it creates real property issues. To address this issue, an alternative method of construction for stabilizing soil was developed and tested by ERDC-CERL during FY17 by using a gravel base and stabilizing it with geopolymer. In this method, mixtures of geopolymer and sand are percolated into loose gravel beds to produce hard surfaces that exhibit nearly the same strength as ordinary concrete. Advantages of this technique include lack of batching, repurposing of industrial waste products, and ease of installation. This report discusses laboratory demonstrations performed by ERDC-CERL to determine a useful range of component ratios, characterize the critical properties of the gravel bed, and identify the most successful application methods. Results indicate that a geopolymer mortar with $35 \%$ wt sand, or $45 \%$ wt sand with additional water, can effectively percolate through an ASTM \#6 gravel bed, resulting in a strong, stabilized platform.

\section{SUBJECT TERMS}

United States-Armed Forces-Military construction operations, Temporary structures (Building), Soil stabilization, Pavements, ConcreteAdditives, Mortar-Additives, Geopolymers

\section{SECURITY CLASSIFICATION OF:}

\section{a. REPORT}

Unclassified b. ABSTRACT

Unclassified

17. LIMITATION
OF ABSTRACT
UU

\begin{tabular}{c|c} 
18. NUMBER \\
OF PAGES
\end{tabular}
HQUSACE NUMBER(S)
10. SPONSOR/MONITOR'S ACRONYM(S)
HQUSACE
$\begin{aligned} & \text { 11. SPONSOR/MONITOR'S REPORT } \\ & \text { NUMBER(S) }\end{aligned}$
\begin{tabular}{l} 
10. SPONSOR/MONITOR'S ACRONYM(S) \\
HQUSACE \\
\hline $\begin{array}{l}\text { 11. SPONSOR/MONITOR'S REPORT } \\
\text { NUMBER(S) }\end{array}$ \\
\end{tabular}

9a. NAME OF RESPONSIBLE PERSON

19b. TELEPHONE NUMBER (include area code) 